\title{
Generating porosity during olivine carbonation via dissolution channels and expansion cracks
}

\author{
Tiange Xing $^{1}$, Wenlu Zhu ${ }^{1}$, Florian Fusseis ${ }^{2}$, and Harrison Lisabeth ${ }^{1,3}$ \\ ${ }^{1}$ Department of Geology, University of Maryland, College Park, MD, USA \\ ${ }^{2}$ School of Geosciences, University of Edinburgh, Edinburgh, UK \\ ${ }^{3}$ Department of Geophysics, Stanford University, Stanford, CA, USA
}

Correspondence: Tiange Xing (tiange@umd.edu)

Received: 2 April 2018 - Discussion started: 13 April 2018

Revised: 20 June 2018 - Accepted: 26 June 2018 - Published: 13 July 2018

\begin{abstract}
The olivine carbonation reaction, in which carbon dioxide is chemically incorporated to form carbonate, is central to the emerging carbon sequestration method using ultramafic rocks. The rate of this retrograde metamorphic reaction is controlled, in part, by the available reactive surface area: as the solid volume increases during carbonation, the feasibility of this method ultimately depends on the maintenance of porosity and the creation of new reactive surfaces. We conducted in situ dynamic X-ray microtomography and nanotomography experiments to image and quantify the porosity generation during olivine carbonation. We designed a sample setup that included a thick-walled cup (made of porous olivine aggregates with a mean grain size of either $\sim 5$ or $\sim 80 \mu \mathrm{m}$ ) filled with loose olivine sands with grain sizes of $100-500 \mu \mathrm{m}$. The whole sample assembly was reacted with a $\mathrm{NaHCO}_{3}$ aqueous solution at $200^{\circ} \mathrm{C}$, under a constant confining pressure of $13 \mathrm{MPa}$ and a pore pressure of $10 \mathrm{MPa}$. Using synchrotron-based X-ray microtomography, the three-dimensional (3-D) pore structure evolution of the carbonating olivine cup was documented until the olivine aggregates became disintegrated. The dynamic microtomography data show a volume reduction in olivine at the beginning of the reaction, indicating a vigorous dissolution process consistent with the disequilibrium reaction kinetics. In the olivine cup with a grain size of $\sim 80 \mu \mathrm{m}$ (coarsegrained cup), dissolution planes developed within $30 \mathrm{~h}$, before any precipitation was observed. In the experiment with the olivine cup of $\sim 5 \mu \mathrm{m}$ mean grain size (fine-grained cup), idiomorphic magnesite crystals were observed on the surface of the olivine sands. The magnesite shows a near-constant growth throughout the experiment, suggesting that the reac-
\end{abstract}

tion is self-sustained. Large fractures were generated as the reaction proceeded and eventually disintegrated the aggregate after $140 \mathrm{~h}$. Detailed analysis show that these are expansion cracks caused by the volume mismatch in the cup walls, between the expanding interior and the near-surface which keeps a nearly constant volume. Nanotomography images of the reacted olivine cup reveal pervasive etch pits and wormholes in the olivine grains. We interpret this perforation of the solids to provide continuous fluid access, which is likely key to the complete carbonation observed in nature. Reactions proceeding through the formation of nano- to micronscale dissolution channels provide a viable microscale mechanism in carbon sequestration practices. For the natural peridotite carbonation, a coupled mechanism of dissolution and reaction-induced fracturing should account for the observed self-sustainability of the reaction.

\section{Introduction}

Mantle peridotites are exposed widely on the Earth's surface in tectonic settings such as mid-ocean ridges, subduction zones and ophiolites (Escartín et al., 1997; Fryer et al., 1995). Peridotite is mainly composed of olivine which is unstable at temperatures below $700^{\circ} \mathrm{C}$ in the presence of water (Evans, 1977) and below $500^{\circ} \mathrm{C}$ in the presence of $\mathrm{CO}_{2}$-rich fluids (Johannes, 1969). The transformation of olivine to serpentine and carbonates due to fluid-rock interaction is extensively observed in peridotite outcrops (e.g., Beinlich et al., 2012; Falk and Kelemen, 2015; Hansen et al., 2005). Rock deformation experiments have demonstrated that fluid alteration to 
peridotite can strongly affect the strength and tectonics of the oceanic lithosphere (Deschamps et al., 2013; Moore et al., 1996). Therefore, study of the olivine-fluid interaction is of great importance for understanding the alteration process of peridotite in a variety of tectonic regions. General peridotite alteration reactions can be formulated as follows (Hansen et al., 2005; Kelemen and Matter, 2008):

$$
\begin{aligned}
& \text { Olivine }+\mathrm{CO}_{2} \text { in fluid }=\text { Magnesite }+ \text { Quartz, } \\
& \mathrm{Mg}_{2} \mathrm{SiO}_{4}+2 \mathrm{CO}_{2}=2 \mathrm{MgCO}_{3}+\mathrm{SiO}_{2}, \\
& \text { Olivine }+\mathrm{CO}_{2} \text { in fluid }+\mathrm{H}_{2} \mathrm{O}=\text { Talc }+ \text { Magnesite, } \\
& \quad 4 \mathrm{Mg}_{2} \mathrm{SiO}_{4}+5 \mathrm{CO}_{2}+\mathrm{H}_{2} \mathrm{O}=\mathrm{Mg}_{3} \mathrm{Si}_{4} \mathrm{O}_{1} \mathrm{O}(\mathrm{OH})_{2} \\
& +5 \mathrm{MgCO}_{3}, \\
& \text { Olivine }+\mathrm{H}_{2} \mathrm{O}=\text { Serpentine }+ \text { Brucite, } \\
& 2 \mathrm{Mg}_{2} \mathrm{SiO}_{4}+3 \mathrm{H}_{2} \mathrm{O}=\mathrm{Mg}_{3} \mathrm{Si}_{2} \mathrm{O}_{5}(\mathrm{OH})_{4}+\mathrm{Mg}(\mathrm{OH})_{2}, \\
& \text { Brucite }+\mathrm{CO}_{2}=\mathrm{Magnesite}+\mathrm{H}_{2} \mathrm{O}, \\
& \mathrm{Mg}(\mathrm{OH})_{2}+\mathrm{CO}_{2}=\mathrm{MgCO}_{3}+\mathrm{H}_{2} \mathrm{O} .
\end{aligned}
$$

Although peridotite weathering reactions occur widely in nature, the rate of olivine carbonation at subsurface conditions is debated. Since the retrograde metamorphic reactions are kinetically fast, the extent of transformation is limited by fluid supply which depends on the accessible fluid pathways. As the hydration and carbonation of olivine results in an up to $\sim 44 \%$ increase in solid molar volume (Goff and Lackner, 1998; Hansen et al., 2005; Kelemen and Matter, 2008), carbonation of olivine is generally assumed to be selflimiting: the reaction products would gradually fill up the pore space and lead to a decrease in the porosity (Emmanuel and Berkowitz, 2006; Hövelmann et al., 2012), which in turn lowers permeability and reduces fluid supply. This negative feedback would ultimately force the alteration to cease. However, naturally occurring completely carbonated peridotites are evidence that these limitations can be overcome. For instance, listvenite is the natural completely carbonated product of peridotite, which is composed of magnesite, quartz and trace minerals (Beinlich et al., 2012; Nasir et al., 2007). This creates a conundrum of how the large extent carbonation can be achieved with the potential self-limitation of reducing fluid pathways.

In order to explain this discrepancy between the theory and the observation, numerous studies have been conducted aiming to find a mechanism to maintain the access for reacting fluid during olivine alteration reactions. In 1985, Macdonald and Fyfe examined naturally altered peridotite and proposed that the large volume change associated with the reaction could generate high local stresses and strains, which would cause episodic cracking. This idea has then been applied to olivine carbonation by Kelemen and Matter (2008), who proposed a positive feedback loop where fractures could be generated during the volume-expanding reaction, porosity and permeability can be maintained or even increased, which in turn would accelerate the carbonation processes (Rudge et al., 2010). In 2011, Kelemen et al. showed that in natural peridotites cross-cutting hierarchical fracture networks filled by synkinematic carbonate and quartz veins extend to microscopic scales. These cross-cutting networks indicate coeval carbonate crystallization and fracturing. Several studies also showed that the forces generated by the volume increase should be enough to fracture peridotite (Iyer et al., 2008; Jamtveit et al., 2009, 2011; Ulven et al., 2014).

While reaction-induced fracturing is accepted as a way to maintain fluid access, the mechanical details of the process are poorly understood. As for the mechanism that generates stresses, "crystallization pressure" (also termed "force of crystallization") has been proposed (e.g., Scherer, 2004; Weyl, 1959; Winkler and Singer, 1972). In this model, the precipitation/crystallization of reaction products exert pressure around the growing crystals, and fracturing takes place when that pressure exceeds the local minimum principal stress (Kelemen and Hirth, 2012). Salt crystallization (Scherer, 2004) is a common example where high crystallization forces due to the nucleation of precipitates in pore space cause samples to "burst from the inside" (see Fig. 1a). However, studies have shown that the crystallization force is low in the olivine carbonation system (e.g., van Noort et al., 2017). Because of the lack of experimental evidence of crystallization forces during olivine alteration, Zhu et al. (2016) proposed an "expansion cracking" mechanism as an alternative model after successfully producing reactioninduced fractures in an in situ synchrotron X-ray microtomography study. In the expansion cracking model, tensile stresses are generated due to the volume mismatch between regions with different precipitation rates, leading to cracks forming in regions that expand slower than their surroundings (see Fig. 1b).

Beyond fracturing, dissolution has been recognized as an important part of the olivine alteration process (e.g., Velbel, 2009; Velbel and Ranck, 2008; Wilson and Jones, 1983) and proposed as a mechanism to explain the observed complete carbonation of peridotite. In 1978, Grandstaff showed that dissolution could significantly increase the surface area through etch pitting. Wilson (2004) suggested that the weathering of olivine is controlled by etch pitting and channel formation due to preferential dissolution, which assists the migration of fluid and promotes further reaction. Andreani et al. (2009) suggested that permeability may be maintained during peridotite carbonation by the development of preferential flow zones. Lisabeth et al. (2017a, b) observed relevant structures in dunite samples that have been reacted under controlled stress conditions and interpreted them as a pattern of secondary porosity bands formed by dissolution coupled to locally intensified compressional stresses.

Previous investigations of olivine carbonation were largely based on the interpretation of naturally deformed samples (e.g., Macdonald and Fyfe, 1985), thermodynamic modeling (e.g., Kelemen and Hirth, 2012) or comparison with reaction systems other than olivine (e.g., leucite to analcime in Jamtveit et al., 2009). While these approaches led to signifi- 

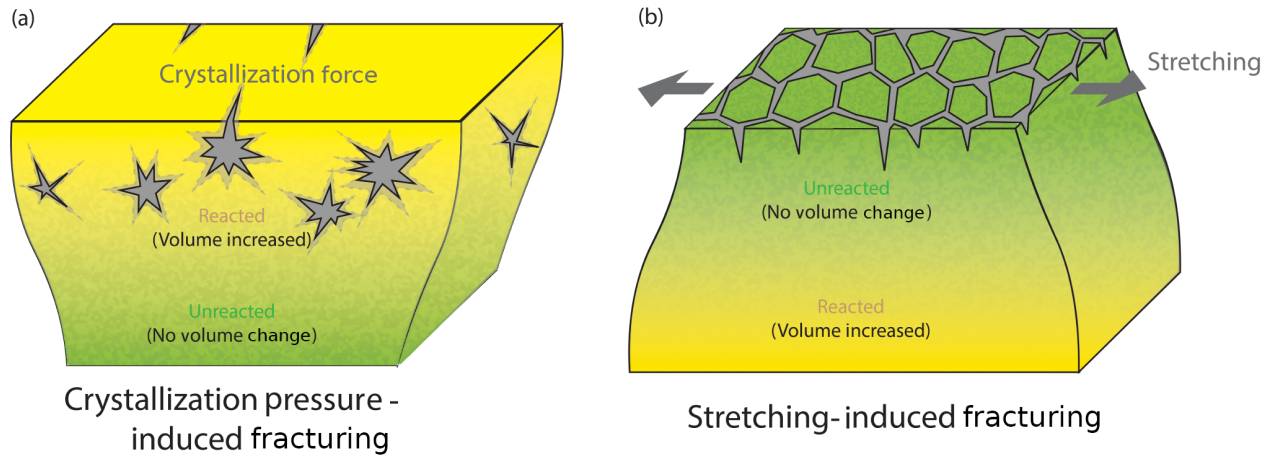

Figure 1. Illustration of the mechanisms of reaction-induced fracturing during olivine-fluid interaction. (a) The crystallization pressurization model describes the development of fractures caused by crystallization forces exerted on the surroundings due to growth of precipitates. Salt crystallization (Scherer, 2004) is a typical example of the crystallization pressure-induced fracturing. The fractures first appear at areas where precipitation is most concentrated and propagate outwards. (b) The surface cracking model describes the development of fractures as a result of a contrast in expansion which causes stretching at the surface. A difference in the precipitation rate between the periphery and interior of the sample causes them to expand at different rates with the interior expanding faster than the surface. This builds up the tensile stress at the surface that fractures the sample and leads to a development of a polygonal fracture network. The fractures propagate from the surface inwards.

cant advancements, there are limitations to the understanding of the mechanisms responsible for porosity generation during olivine carbonation that these approaches can provide. The history of natural fault rocks is inevitably complex, and thermodynamic arguments and numerical models can only indicate a potential, while the actual progress of chemical reactions is strongly affected by interfacial structures, which vary considerably in different mineral systems. Thus, it is critical to complement such studies with laboratory experiments on olivine carbonation.

Synchrotron-based X-ray tomography is an advanced nondestructive method to capture three-dimensional images of materials. Where processes affecting these materials are followed through time, a four-dimensional (three spatial dimensions plus time) dataset is captured. By using X-ray transparent reaction cells (Fusseis et al., 2014b), the technique enables the investigation of fluid-rock interaction at controlled and geologically relevant conditions. We examined the carbonation process of olivine on the basis of four-dimensional images acquired by X-ray microtomographic imaging with synchrotron radiation at the Advanced Photon Source. Zhu et al. (2016) hypothesized that large grains would be preferred sites for precipitation of new crystals, and the contrast in the grain size produced the volume mismatch due to a preferred precipitation on the larger grains and led to the fracturing of the sample. To further test the hypothesis, in the current study, we conducted a new experiment using an olivine aggregate with larger grain size $(80-100 \mu \mathrm{m})$ compared to the previous experiment reported by Zhu et al. (2016; 0-20 $\mu \mathrm{m})$. We also performed advanced 3-D analyses and quantification of the micro- and nanotomography data obtained by Zhu et al. (2016). In an advancement of the results presented by Zhu et al. (2016), here we present direct evidence for the coupled mechanisms of dissolution and precipitation-driven fracturing during olivine carbonation and demonstrate their importance in sustaining the reaction progress at different spatial and temporal scales. We further show direct evidence of how reaction-induced fracturing operates, i.e., how stress is generated through volume-increasing reactions. A better understanding of olivine carbonation directly applies to the geological sequestration of $\mathrm{CO}_{2}$ (Gislason et al., 2010; Mani et al., 2008). The principle of in situ carbon mineralization is the conversion of silicate and hydroxide minerals to form carbonate minerals as a stable sink for $\mathrm{CO}_{2}$ (Power et al., 2013). Peridotite, because of its wide occurrence and high reactivity, is considered one of the best potential feedstocks for $\mathrm{CO}_{2}$ mineralization (Andreani et al., 2009; Beinlich and Austrheim, 2012); the estimated rate of $\mathrm{CO}_{2}$ consumption peridotite carbonation could be as high as $2 \times 10^{9} \mathrm{t} \mathrm{km}^{-3}$ per year (Kelemen and Matter, 2008). As the dominant constituent of peridotite, olivine becomes the most important mineral for $\mathrm{CO}_{2}$ mineralization. Our study provides new insights into carbon sequestration using ultramafic rocks, and our findings on the mechanism of fracture generation during olivine carbonation could provide guidance to industrial applications.

\section{Experimental setup}

\subsection{Sample configuration}

In Zhu et al. (2016), the contrast in grain size between the loose grains and the cup wall aggregate is hypothesized as the cause of the non-uniform precipitation which is crucial to the generation of fractures in the experiment. Here, we use coarse-grained olivine aggregate in the cup wall to reduce the 
(a)

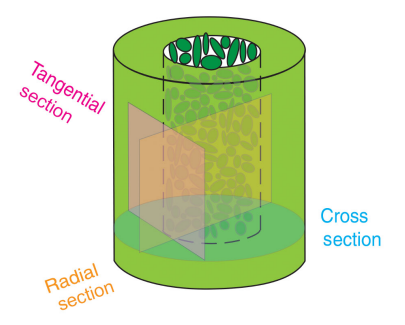

(b)

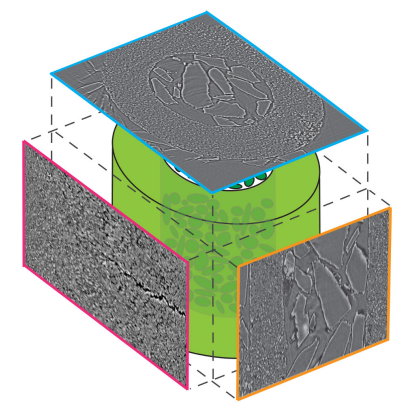

Figure 2. Illustration of sample configuration. (a) The sample is composed a sintered olivine aggregate cup with loose olivine sand fillings (grain size 100-500 $\mu \mathrm{m}$ ). Quantitative microtomographic analyses are conducted on the tangential (pink), radial (orange) and cross (blue) section of the sample. (b) Example of the tomographic image that was used in the 2-D examination of Zhu et al. (2016).

contrast in grain size between the cup wall and the fillings and further test their hypothesis.

The sample assembly consists of a millimeter-sized synthesized San Carlos olivine cup, filled with loose San Carlos olivine sand (grain size 100-500 $\mu \mathrm{m}$; see Fig. 2a) and then covered by a lid made of the same material as the cup. Both the olivine cup and its lid are taken from a sintered pellet made from pulverized San Carlos olivine with a grain size of $80-100 \mu \mathrm{m}$. This coarse-grained olivine cup is referred to as large grain cup (LGC) in the following discussion. Data obtained from the LGC experiment will be compared to the results of an olivine carbonation experiment conducted by Zhu et al. (2016) at the same experimental conditions, on a fine-grained (grain sizes between 0 and $20 \mu \mathrm{m}$ ) cup. The finegrained olivine cup is referred to as the small grain olivine cup (SGC) in the following discussion.

The cup, which was fabricated by heat pressing in a procedure described in Zhu et al. (2016), has inner and outer diameters of 1 and $1.8 \mathrm{~mm}$, respectively, with a resulting wall thickness of $\sim 0.4 \mathrm{~mm}$. The initial porosity of the cup is $\sim 10 \%$. Both LGC and SGC samples were sintered for $4 \mathrm{~h}$ at $1400^{\circ} \mathrm{C}$, the LGC sample came out weaker (less cohesive) compared to the SGC sample, and the initial porosity of LGC is slightly higher than that of SGC.

The loose grains inside the cup allowed the inspection of magnesite growth on free olivine surfaces. The sample assemblies (i.e., olivine cup and loose grains) were jacketed and loaded into an X-ray transparent pressure cell (Fig. 3). A confining pressure of $13 \mathrm{MPa}$ and a pore fluid of $\mathrm{NaHCO}_{3}$ aqueous solution $\left(1.5 \mathrm{~mol} \mathrm{~L}^{-1}\right)$ at $10 \mathrm{MPa}$ were applied to the sample. The pore pressure downstream is regulated by a pressure regulator while the pressure upstream is controlled by a syringe pump to form a semi-open system. Both upstream and downstream pore pressures were maintained at $10 \mathrm{MPa}$ throughout the experiment. A small axial load is applied independently from the confining pressure by locking the pis-

ton at a fixed position. The pressure cell was then heated to $20{ }^{\circ} \mathrm{C}$ to initiate the reaction. These conditions were kept constant during the entire microtomography experiment. The reaction of the LGC sample was stopped at $36 \mathrm{~h}$ after considerable secondary porosity generation was observed. No magnesite precipitation was detected in LGC. The SGC sample reacted for 7 days until intense fracturing was observed. Significant magnesite precipitation was detected in SGC (Zhu et al., 2016).

\subsection{Micro- and nanotomography}

Third-generation synchrotron facilities produce electromagnetic radiation bright enough to allow rapid imaging even inside experimental vessels, thereby enabling studies of dynamic processes ranging over periods from seconds to days, while acquiring individual three-dimensional (3-D) datasets in fractions of a second. Synchrotron X-ray microtomography has therefore become one of the most powerful tools in structural geology and rock mechanics studies (see Fusseis et al., 2014a for a review and Bedford et al., 2017 for a recent application).

In this experiment, synchrotron-based X-ray absorption microtomography has been used to record the dynamic carbonation of olivine in four dimensions. We used an X-ray transparent cell (Fusseis et al., 2014b), mounted in the upstream experimental station at beamline 2BM of the Advanced Photon Source of the Argonne National Laboratory, $25 \mathrm{~m}$ from the source. There, a polychromatic beam filtered by $1 \mathrm{~mm}$ aluminum, $15 \mathrm{~mm}$ silicon and $8 \mathrm{~mm}$ borosilicate glass yielded a photon flux with an energy peak at $65 \mathrm{keV}$ (Zhu et al., 2016). A Cooke pco.edge sCMOS camera with $2560 \times 2160$ pixels (pixel size $6.5 \times 6.5 \mu \mathrm{m}^{2}$ ) was used in a flying scan mode. The sample-detector distance was $300 \mathrm{~mm}$, which introduced a clear phase contrast signal to the data (Cloetens et al., 1996). The camera recorded projections from a $10 \mu \mathrm{m}$ thick LuAG:Ce single crystal scintillator, magnified through a $10 \times$ Mitutoyo long-working distance lens yielding a pixel size of $0.65 \mu \mathrm{m}$. Projections were collected with an exposure time of $50 \mathrm{~ms}$ while the sample was rotated over $180^{\circ}$ with $1.2^{\circ} \mathrm{s}^{-1}$. A total of 1500 projections were collected in $150 \mathrm{~s}$. For the LGC sample, 115 3-D microtomographic datasets were acquired over $36 \mathrm{~h}$, together forming a 4-D dataset, with time as the fourth dimension. For the SGC sample, 379 datasets were acquired over 7 days. From these 379 datasets, 19 were chosen for further detailed quantitative analysis. All acquired microtomographic data were reconstructed using the code Tomopy (Gürsoy et al., 2014) into stacks of 2160 images each, with dimensions of $2560 \times 2560$ pixels per image. Each of these image stacks contains a three-dimensional representation of the sample mapped onto a 32 bit image, with the grey values reflecting the local absorption of X-rays (Fusseis et al., 2014a). Where the refractive indices change in the sample, i.e., on edges, this absorption signal is locally overlain by a phase contrast 


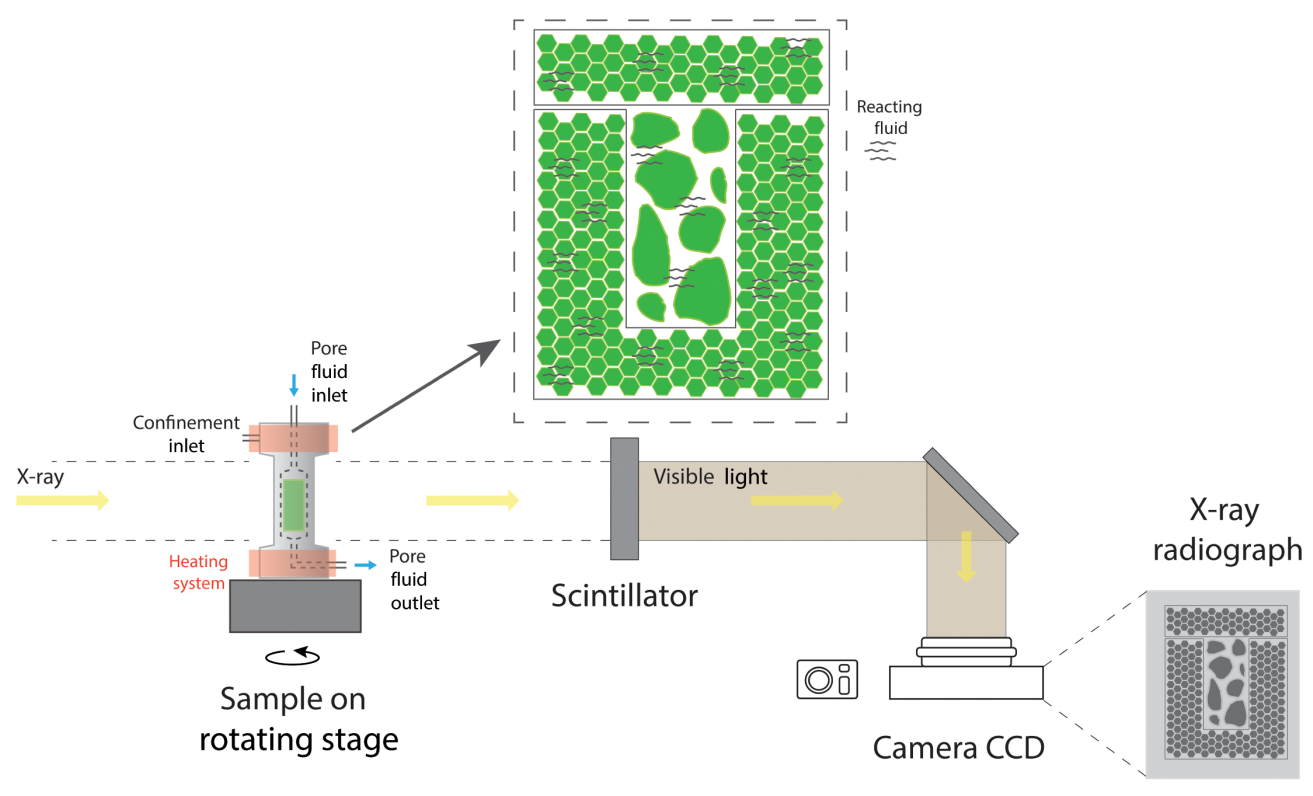

Figure 3. Experimental setup for dynamic microtomography. Inside the X-ray transparent pressure cell, the confining pressure, pore pressure and temperature can be controlled independently. The synchrotron radiation imaging records radiographs of the sample at in situ conditions with ongoing reaction at different angular positions with the sample being rotated.

signal (Cloetens et al., 1996). The time series dataset covers the entire duration of the experiment.

After the in situ acquisition of the microtomography images, a fragment of the cup wall from the SGC was taken to conduct nanoscale imaging. Nanotomography was conducted using a transmission X-ray microscope (TXM) at the beamline 32-ID of the Advanced Photon Source of the Argonne National Laboratory. A monochromatic beam of Xray with an energy of $8 \mathrm{keV}$ was used. An X-ray objective lens corresponding to a Fresnel zone plate with $60 \mathrm{~nm}$ outermost zone width was used to magnify radiographs onto a detection system assembly comprising a LuAG scintillator, a Zeiss $5 \times$ optical microscope objective lens and an Andor Neo sCMOS camera. Nanotomography yields a pixel size of $\sim 60 \mathrm{~nm}$ after binning.

\subsection{Image processing procedures}

Zhu et al. (2016) conducted preliminary analyses and measurements on two-dimensional (2-D) image slices (see Fig. 2b) of SGC through the 3-D microtomography datasets acquired. Here, we present the results of a true 3-D volume quantification of the microstructural changes in the SGC sample (i.e., spatiotemporal changes in grain and pore volumes) and compare them with the results obtained from LGC sample in this study.

In both the SGC and the LGC samples, a subregion that included both the cup wall near-surface as well as the cup wall's interior was chosen for detailed inspection from all datasets. For each sample, two subvolumes with the dimension of $400 \times 400 \times 400$ voxels were cropped out from the region of interest in the cup wall (see Fig. 4, subvolumes 1 and 2 from SGC and subvolumes 3 and 4 from LGC). In the SGC sample, subvolume 2 was further cropped to a volume of $247 \times 400 \times 400$ voxels $\left(160.55 \times 260 \times 260 \mu \mathrm{m}^{3}\right)$ to eliminate the boundary of the cup wall.

Image segmentation is the separation and extraction of phases of interests from the 3-D datasets for further analysis and quantification. A large range of segmentation algorithms exists (e.g., Kaestner et al., 2008). In global binary thresholding, images are segmented by identifying the grey value range representing a phase and assigning all voxels within that range a single value (usually 1 ) while all other voxels are classified as matrix (and assigned a different single value, usually 0) (Heilbronner and Barrett, 2014). Global binarization was conducted in Avizo Fire 8 to isolate pores from solids.

In the SGC sample, at the given spatial resolution, we could not resolve the new crystals that precipitated within the cup wall and only the pore space was segmented there. Pixels with grey values that fall in the range $(-0.00031$, $-0.000077)$ were assigned to pore space. We used the segmented data to quantify the change in the spatial distribution of pores during the experiment. Each subvolume was further divided into smaller cubes (side lengths $\sim 26 \mu \mathrm{m}$ ) in which the average porosity is calculated to examine where changes in porosity occurred. In the LGC sample, grey values that fall 
(a) SGC

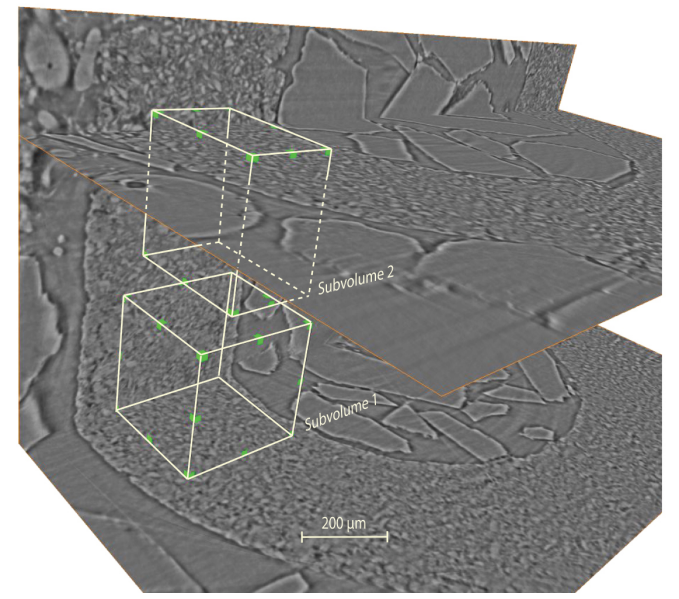

(b) LGC

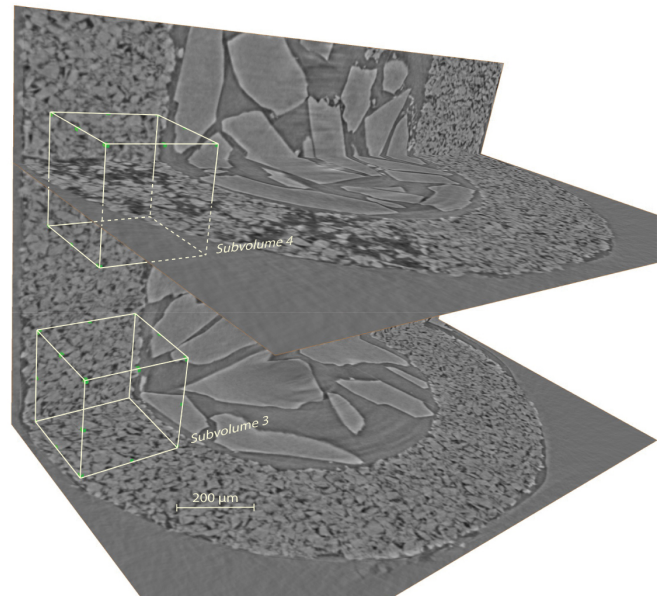

Figure 4. Positions of the subvolumes in the cup wall of (a) SGC and (b) LGC, where quantitative 3-D microstructure analyses were performed. In the SGC sample, subvolume 1 (bottom box) is located at the center of the cup wall. Subvolume 2 (top box) is located adjacent to the outer rim of the wall. In the LGC sample, both subvolume 3 (bottom box) and subvolume 4 (top box) are located at the center of the cup wall.

in the range $(-0.00031,-0.000095)$ were assigned to pore space.

In the nanotomography data, the grey value range $\left(2.97672 \times 10^{-9}, 0.13161\right)$ was assigned to pore space. In these data, the olivine is represented by grey values in the range $(0.30846,1.3161)$. Voxels with intermediate grey values $(0.13161,0.30846)$ were assigned to reaction precipitates (e.g., magnesite).

\section{Data analysis and results}

We have observed the development of secondary porosity during the reaction in both the LGC and SGC experiments (Fig. 5). Detailed examination has further revealed that the porosity generation in LGC is significantly different from that in SGC.

\subsection{Dissolution in the LGC sample}

As the reaction proceeded, olivine grains in the LGC sample shrank in size and secondary pores were produced (Fig. 5a). This suggests that dissolution dominated the carbonation reaction in LGC, with little precipitation detected. The secondary pore space formed first at the center of the cup wall and grew outwards (Fig. 5a), which is opposite to that in SGC where fractures grew from the surface of the cup wall inwards (Fig. 5b).

Planar fractures formed within $36 \mathrm{~h}$ of reaction in LGC (Fig. 6), and the experiment was stopped shortly after the formation of these fractures. Because of the lack of precipitation, these planar fractures could not be induced by the non-uniform volume expansion as in the SGC sample (Zhu et al., 2016). Under a constant confining pressure, volume reduction in olivine grains (i.e., dissolution) likely shortened the LGC sample length as the reaction proceeded. Because the axial piston was kept at a fixed position during the experiment, this shortening in sample length resulted a decrease in axial stress. Because the LGC sample is mechanically weak (less cohesion), even though the reduction in axial stress is small, it could be sufficient to cause fracture in LGC in the manner of dilation bands under triaxial extension (e.g., Zhu et al., 1997). Detailed examination of the 3-D images revealed the disappearance of small grains along the plane which is clear evidence of dissolution. Thus, we refer to these planar cracks as dissolution-assisted fractures under triaxial extension. The dissolution-assisted fractures were not observed in the SGC sample because it is much stronger due to its fine grain size (e.g., Eberhardt et al., 1999; Singh, 1988). The triaxial extension stress condition would be no longer present once precipitation started (after $\sim 36 \mathrm{~h}$ ) and sample volume expansion took place.

\subsection{Lack of precipitation in the LGC sample}

Evidence from direct observation and quantitative analysis has shown that the LGC sample has a lack of precipitation.

Within the duration of the reaction, hardly any precipitation was observed in the cup wall. In the microtomographic images, the surface layer of the loose olivine grains remained free of precipitates. Both sides of the cup wall remained straight and showed no spalling due to precipitation-caused non-uniform stretching. The sample did not experience any expansion as seen in the SGC sample.

Apart from the direct observation, grey value histograms of the data also show evidence of lacking precipitation in 

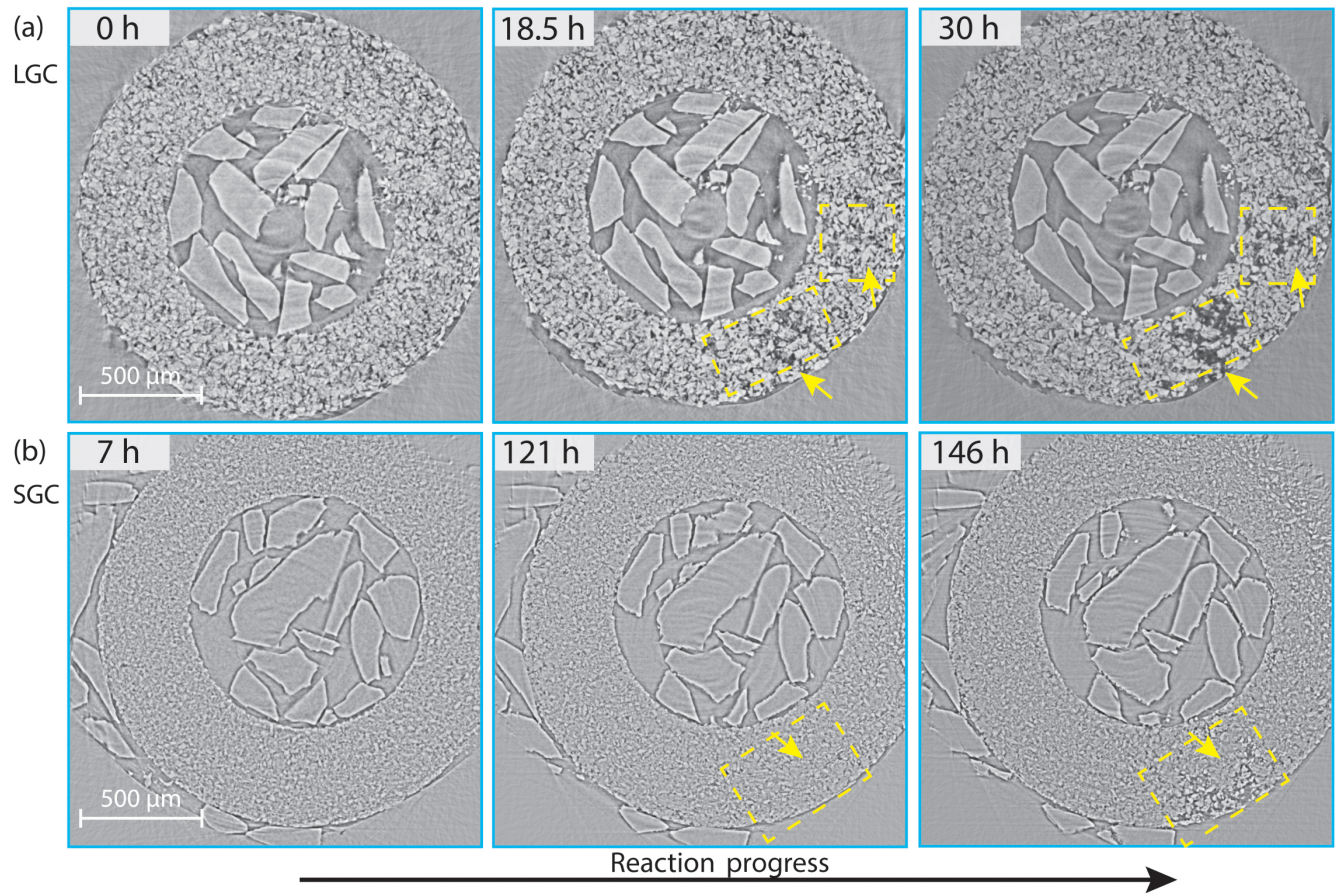

Figure 5. Reconstructed images showing the cross-section view of the sample undergoing olivine carbonation. (a) In the LGC sample, original olivine grains shrink, and secondary pore space appears (yellow arrows), suggesting dissolution of olivine. Most of the large pore spaces concentrate at the interior of the cup wall (highlighted by yellow dashed lines). (b) In the SGC sample, the fractures first developed at the surface of the cup and propagated from the outer rim into the cup wall (highlighted by yellow dashed lines). Larger pore space distributes mainly near the rim.
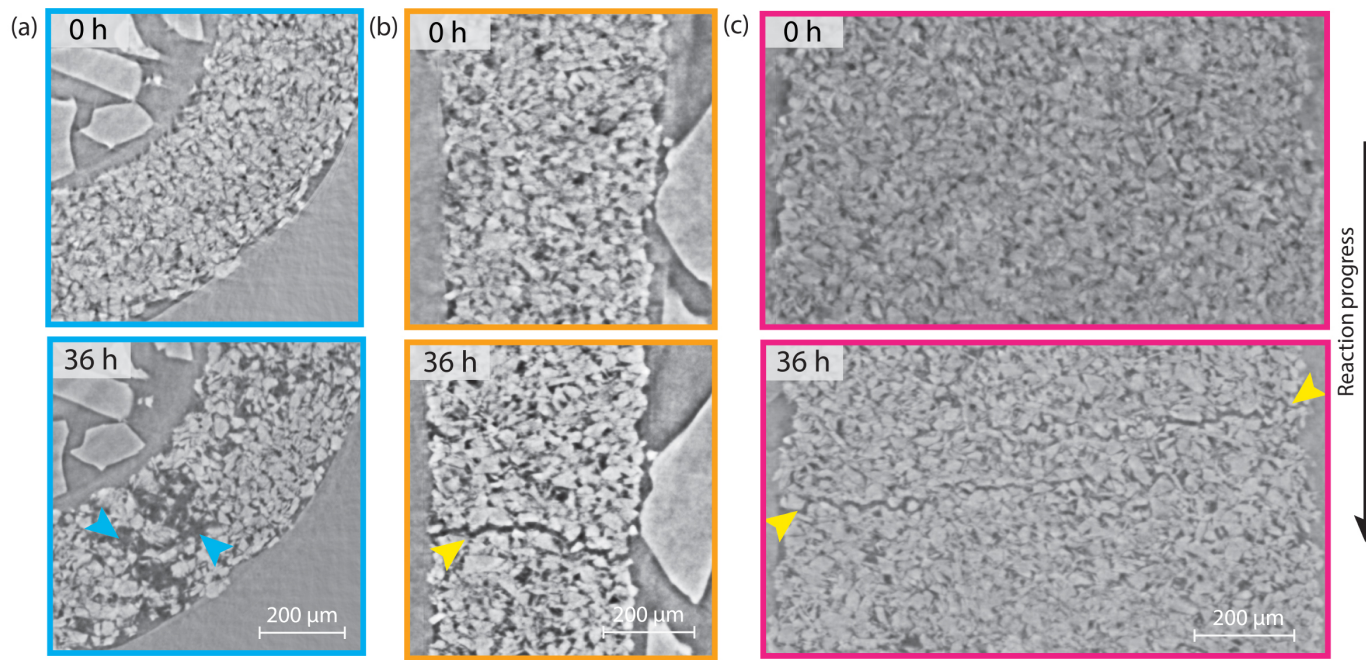

Figure 6. (a) Dissolution features in the cross-sectional images of the LGC sample. 3-D examination reveals that these dissolution features (blue arrowheads) are associated with planar fractures (yellow arrowheads) appeared in (b) the radial and (c) the tangential section images. The boarder color of each section corresponds to color code given in Fig. 2.

the LGC sample. The grey value histograms of 4-D microtomography data evolve systematically during in situ experiments, which can be utilized in the evaluation of the reaction progress (Fusseis et al., 2012). Systematic analysis of the his- tograms of the grey value distribution revealed the progression of reaction during the experiment (Fig. 7).

Comparing the histogram of SGC sample with the LGC sample, the shape of the histograms from the LGC sample 


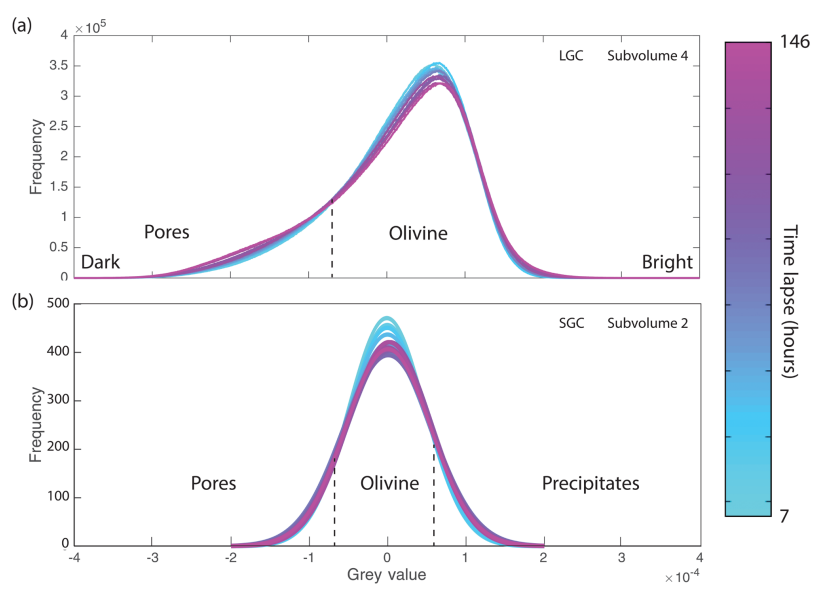

Figure 7. Best fits for the grey value distribution histograms of the sample at different stages of the reaction in (a) subvolume 4 from LGC sample and (b) subvolume 2 from SGC sample. Different colors represent time lapses as shown. Pores, olivine and precipitates are identified based on their grey value ranges. Higher values correspond to lighter grey (solids). The more negative a value is, the darker the grey color becomes (e.g., pores are black). Histograms of the SGC sample were calculated from a 2-D image (Zhu et al., 2016), whereas the histograms of the LGC sample were calculated from 3-D datasets.

(Fig. 7a) is clearly asymmetric compared to the bell-shaped histograms in the SGC sample (Fig. 7b). The slope on the precipitation side of the LGC histogram is steep and becomes steeper as the reaction proceeds, indicating dissolution of olivine with little to no precipitation. The slope on the pore side of the LGC histogram becomes shallower due to the secondary porosity generation due to the dissolution of olivine.

Data from the SGC sample showed that the histograms became uniformly flatter and wider over the duration of the experiment, with an increase in the number of both the darkest and brightest voxels at the expense of the voxels with intermediate grey values. These systematic changes in the absorption behavior can only be caused by the sample reacting and indeed reflect the dissolution of olivine, the generation of pore space and the precipitation of reaction products, in addition to phase contrast around newly generated edges in the sample. The best-fit curves to the histograms evolved systematically during the reaction and intersected in a relatively narrow grey value range $(-0.000077,-0.000055)$ (Fig. 7). Voxels with grey values darker than -0.000077 correspond to fluid-filled pores, whose volume proportion increases throughout the reaction process.

\subsection{Porosity evolution of LGC compared to SGC}

Pore space development in LGC is significantly different from SGC. As shown in Figs. 5 and 6, the secondary pore space in the LGC developed simultaneously at the interior

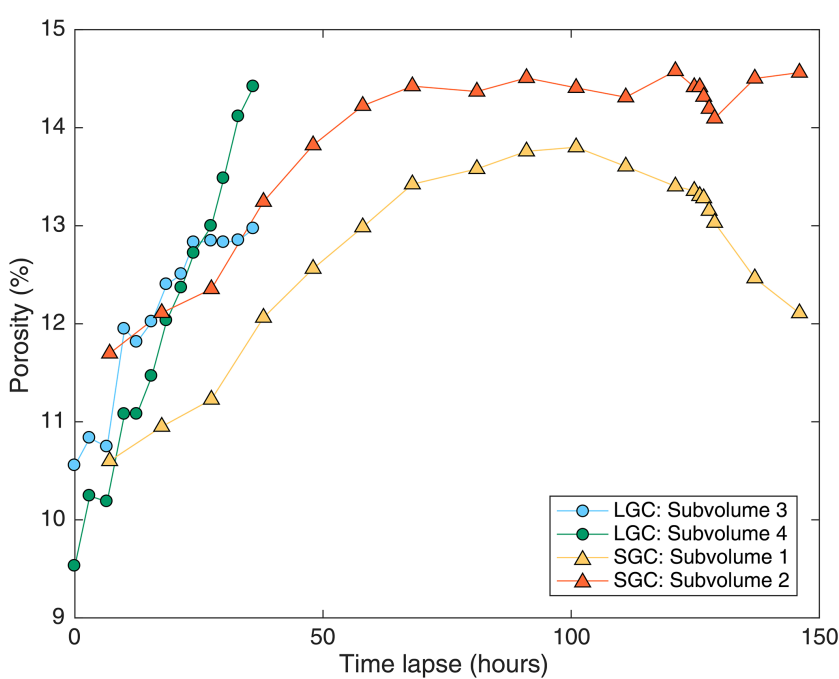

Figure 8. Comparison of porosity evolution in LGC (this study) versus SGC reported by Zhu et al. (2016).

and the near-surface area of the sample. However, in the SGC sample, pore space first occurred in the area close to the surface and propagated inwards.

To further examine the difference in porosity generation of the LGC and SGC samples during the reaction, pore spaces within the subvolumes are segmented from the images and calculated. Figure 8 compares the porosity of subvolumes 1 and 2 (Zhu et al., 2016) from SGC and subvolumes 3 and 4 from LGC samples. As shown by the figure, initial porosity of the LGC and SGC samples is similar. The rate of porosity increase in the LGC sample is similar to the SGC during the first $36 \mathrm{~h}$ after the reaction started. Porosity of the LGC sample is increasing throughout the duration of the experiment while porosity of the SGC shows a decrease after $90 \mathrm{~h}$ of reaction. In the LGC sample, the porosity increased $\sim 5 \%$ and likely resulted from dissolution. This is consistent with other studies that showed the precipitates do not occur in olivine carbonation within $36 \mathrm{~h}$ of reaction (e.g., Lisabeth et al., 2017a).

We then further evaluated the porosity distribution within the subvolumes by quantifying the porosity of the 2-D tangential slice along the samples' radial direction. Figure 9 compares the porosity distribution of subvolume 2 from the SGC sample with subvolume 4 from the LGC sample. Subvolume 4 shows a homogeneous increase in porosity of $\sim 5 \%$ throughout the entire subvolume. Subvolume 2, while showing an increase of porosity during the first $30 \mathrm{~h}$ of the reaction, starts to show a porosity decrease in areas close to the center of the cup wall after $81 \mathrm{~h}$ of reaction. Comparison of the subvolumes from SGC and LGC revealed that the porosity generation within the LGC sample is relatively homogeneous while the porosity generation within the SGC sample starts to show contrast between the cup's near-surface area and its interior after $81 \mathrm{~h}$ of reaction. Results from the 
porosity evaluation further support the finding that the LGC sample is dominated by dissolution with no presence of precipitation.

\subsection{Fractures in LGC versus SGC}

As discussed in Sect. 3.1, the planar fractures observed in the LGC sample are likely a result of the dissolution-assisted extensional crack. This is different from the stretching-induced fractures in SGC (see Zhu et al., 2016) where non-uniform precipitation is indispensable. The dissolution-assisted fracturing in LGC and the stretching-induced fracturing in SGC both generated secondary pore space during the experiments, but the fractures in LGC differ distinctively from those in SGC in many ways:

- Firstly, the dissolution-assisted fracturing is a single, planar feature in 3-D with no obvious secondary fractures branching out, while the fractures observed in the SGC sample formed a network of intersecting cracks. Figure 10a shows the morphology of the dissolution plane and the fracture network in 3-D. It is shown in Fig. 10b that the fractures intersected with each other and formed a complex wedge shape network with the vertex pointing towards the sample's interior. The dissolution-assisted fracturing mainly developed along a plane and shows less intersection with other features.

- Secondly, the LGC sample dominated by dissolution features shows clear evidence for shrinkage of larger grains and disappearance of smaller grains at the interior of the aggregate (Fig. 5a). The SGC sample exhibits patches that develop during the reaction which are evidence for the reaction product precipitation (Zhu et al., 2016).

- Thirdly, the development of micron-scale dissolution is simultaneous, with the shrinkage of grains occurring both at the surface and the interior of the cup wall (Figs. 5 and 6a). In contrast, development of the reaction-induced fracturing is successive with most fractures occurring first at the surface and migrating towards the interior of the cup wall. This caused the observed wedge shape of the fracture network (Fig. 10b). Development of the fractures also exhibits a hierarchical sequence with main fractures appearing first. The secondary fractures branch out from the main fracture and divide the sample into smaller domains (Fig. 2 from Zhu et al., 2016).

- In addition, no precipitates were observed along planar dissolution features in the LGC sample; the cup wall remains straight throughout the experiment. But for the SGC, the cup wall shows clear spalling, which is a sign of non-uniform expansion that links to precipitation in this experiment.

\subsection{Dissolution and fracturing of individual olivine grain}

The reaction affected not only the aggregate but also the individual olivine grains. Both the dissolution and fracturing are observed at grain scale in the SGC sample. Figure 11 shows a series of image slices through a nanotomography dataset, moving through an olivine grain in the cup wall. The grains clearly exhibit channels (etch pits) in the reaction zone. In video S1 (see the Supplement), it can be seen that these channels penetrate into and even through olivine grains. As we do not observe any precipitation filling or clogging the tubes, it is therefore reasonable to think that the channels start as etch pits and grow deeper with the advancing of dissolution and eventually become the through-going channels observed here. The tubular shape and the depth of penetration indicate that they are "wormhole" features, likely resulting from dissolution. The shape and the width of these channels vary, with wider inner channel diameters below the surface suggesting more extensive dissolution at depth. On average, most typical tubes have an inner diameter of around $720 \mathrm{~nm}$.

The fracturing is also observed on individual grains at nanometer scale. Figure 12 shows nanotomographic evidence for hierarchical fracturing within olivine grains. The secondary fractures developed from the primary fracture and formed in a direction that is perpendicular to the earlier ones.

In the reconstructed microtomographic images of the loose grains from the SGC, we observed the precipitation of secondary minerals on the surface of the olivine grains inside the cup (Fig. 13). On the basis of their rhombohedral shapes, we identified these as magnesite crystals. However, the phase contrast between the precipitates and olivine grains is very small, and at the current spatial resolution of $\sim 2 \mu \mathrm{m}$, we could not segment precipitates from olivine grain with acceptable uncertainties. Other minerals (serpentine, brucite, etc.; see Reactions (R1)-(R4)) were likely also present in the sample but could not be isolated at the given image resolution. Measurement of the magnesite circumference revealed continuous growth during the experiment (see Fig. 5 in Zhu et al., 2016). The first magnesite crystals emerged after $48 \mathrm{~h}$, and grains kept nucleating and growing after that. Growth continued until the experiment was aborted and no deceleration could be observed at any point, which indicates that the sample continued reacting. We determined a growth rate for the grain perimeter of $0.772 \mu \mathrm{m} \mathrm{h}^{-1}$, which, by assuming cubic shape of the crystal, yields an equiva-

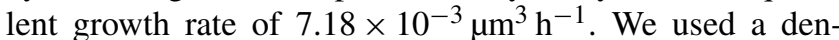
sity of $3.01 \mathrm{~g} \mathrm{~cm}^{-3}$ and molar weight of $84.314 \mathrm{~g} \mathrm{~mol}^{-1}$ for magnesite $\left(\mathrm{MgCO}_{3}\right)$ in our calculation. Assuming a specific reaction surface of $50 \times 50 \mu \mathrm{m}^{2}$, this gave a magnesite growth rate of $2.85 \times 10^{-15} \mathrm{~mol} \mathrm{~cm}^{-2} \mathrm{~s}^{-1}$. This is in general in agreement with the calculation of Saldi et al. (2009).

The volume change of a loose olivine grain inside the cup was calculated to quantify the competing effect of dissolution and precipitation during olivine carbonation. Individual 
(a) LGC Subvolume 4

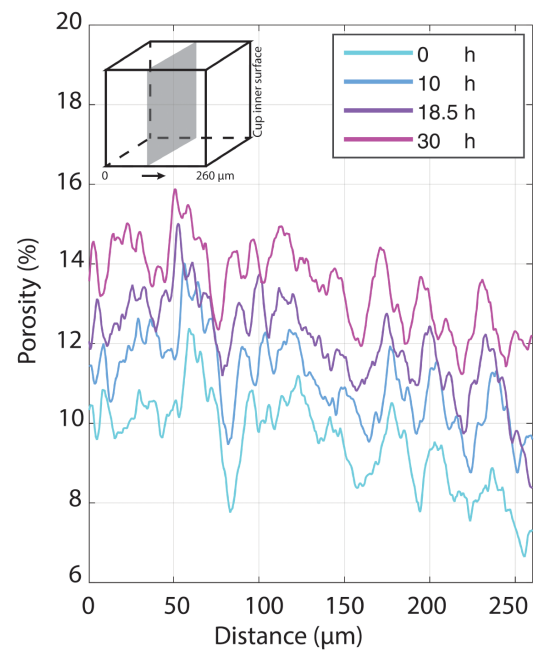

(b) SGC Subvolume 2

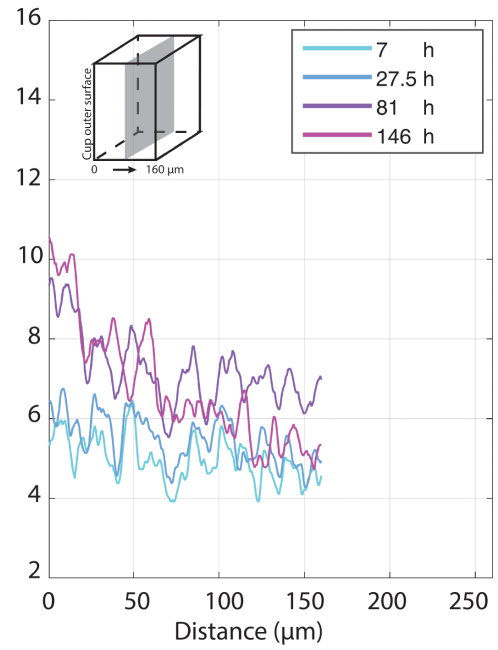

Figure 9. Porosity profiles of (a) LGC and (b) SGC along the radial direction of the sample cup. Different colors indicate reaction time lapse.

(a)

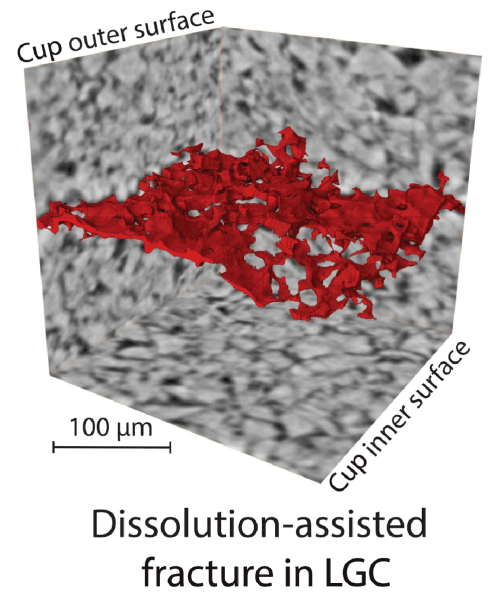

(b)

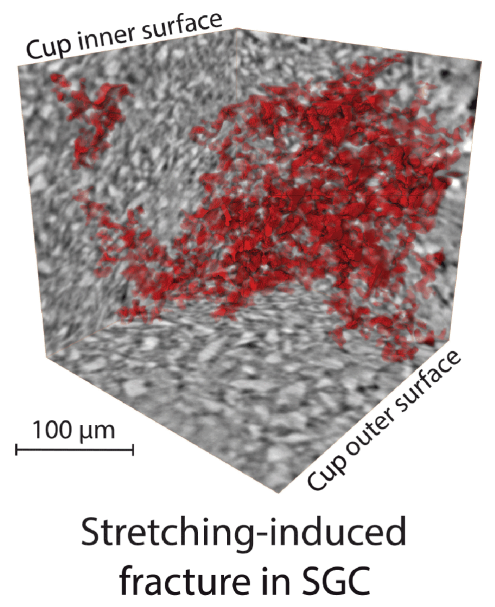

Figure 10. The 3-D geometry (in red) of (a) dissolution-assisted fracture in LGC is distinctively different from (b) the stretching-induced fractures in SGC. Both displayed volumes are $260 \times 260 \times 260 \mu \mathrm{m}^{3}$ in size.

grains were labeled from the segmented data and their volumes determined. Figure 13 plots the volume change of a single grain selected from the loose grains inside the SGC over 13 successive microtomographic datasets (covering 146h). Magnesite overgrowth causes a significant roughening of the olivine grain surface. While the volume of the individual magnesite grain steadily increased throughout the reaction (Zhu et al., 2016), the total volume of the grain (olivine plus precipitates) fluctuates from time to time, which reflects variable rates both in the precipitation of magnesite as well as in the dissolution of olivine. A large drop in grain volume occurred at around $38 \mathrm{~h}$, which is consistent with a period of vigorous olivine dissolution. The largest continuous grain volume increase took place between 40 and $70 \mathrm{~h}$, caused by the precipitation of magnesites. At $\sim 70 \mathrm{~h}$, the grain volume again decreased considerably, indicating that dissolution became dominant once more. This second dissolution episode coincides with the appearance of reaction-induced fractures in the aggregate wall at $\sim 68 \mathrm{~h}$, suggesting a positive feedback process.

\section{Discussion}

We claim that our experimental observations indicate the activity of two different mechanisms that both create fluid pathways effectively. These are dissolution-dominated fluid pathway generation at micrometer scale in the case of the LGC experiment and at nanometer scale in the case of SGC, and reaction-induced fracturing in the case of the SGC. We detail our interpretation in the following sections. 

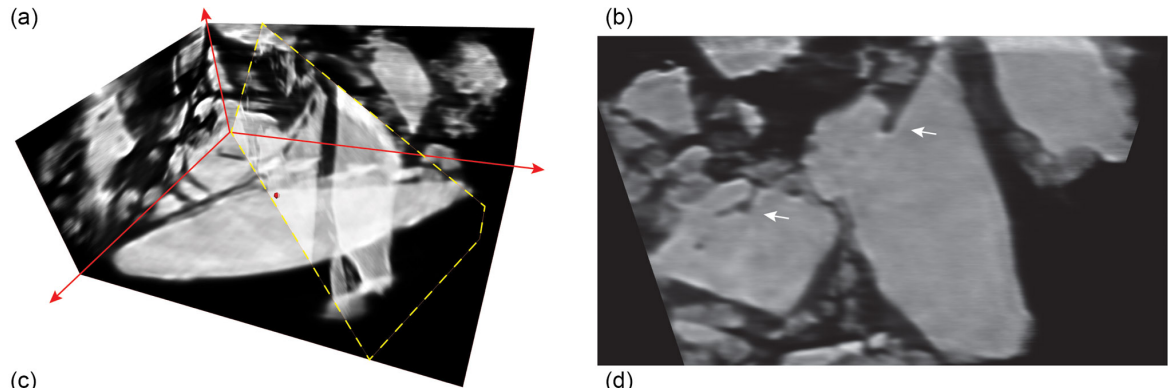

(c)

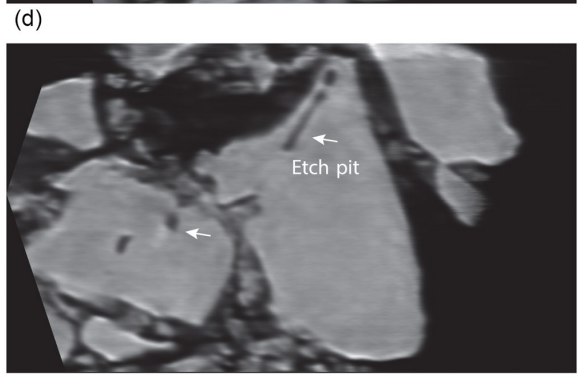

Figure 11. Reconstructed images from the nanotomography data of the SGC sample's cup wall demonstrate the existence of etch pits and dissolution channels (white arrows) formed in the olivine grain. The precipitates (darker grey) partially fill the pore space (black) between olivine grains (lighter grey). The yellow dashed line (a) marks the orientation of the cross sections (b-d). The vertical distance between each 2-D cross section is $\sim 600 \mathrm{~nm}$. Reacting fluid causes a preferential dissolution of the grain which develops small channels that dig into the grain. These features provide a fluid path and eventually break grains, exposing new reactive surfaces.

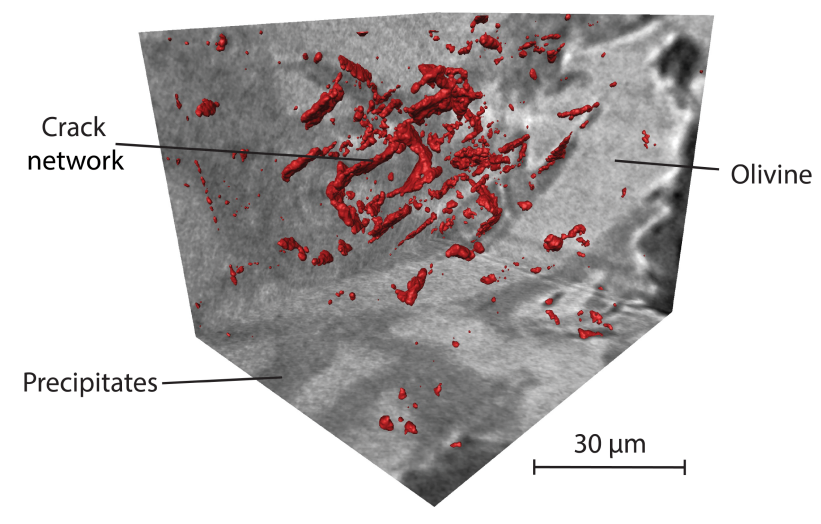

Figure 12. Network of microcracks (red) in the reaction olivine cup wall from SGC shows a polygonal pattern. The dissolution channels make the grain (light grey) more susceptible and a stress concentration is also likely to occur around the etch pits.

\subsection{Dissolution and etch pitting}

Dissolution and etch pitting are important mechanisms that affect the grains' surface morphology and the permeability of the sample (e.g., King et al., 2010; Røyne and Jamtveit, 2015). The nanotomographic observation, that etch pitting incurs extensive dissolution beneath grain surfaces, was also documented by Lisabeth et al. (2017a, b) during the carbonation of dunites. Peuble et al. (2018) also observed nanometerscale veinlets forming oblique to subvertical channels in partially carbonated olivine grains during percolation experi- ment. The hollowing out of olivines seems especially important in areas where the grain boundary porosity is decreasing due to the precipitation of secondary minerals. There, subsurface dissolution channels in olivine grains preserve important fluid pathways and maintain the reaction. This supports the hypothesis of Andreani et al. (2009) that the permeability can be maintained by the preferential dissolution even in the cases where the overall porosity is decreasing. Apart from providing access for fluids, subsurface dissolution features also make the grain more susceptible to fracturing and thereby promote the generation of fracturing observed in the experiment.

The permeability of these dissolution channels was calculated using Hagen-Poiseuille's law (Poiseuille, 1844) and Darcy's law (Darcy, 1856). Hagen-Poiseuille's law allows the calculation of the fluid flow inside a tube in dependency of the pressure gradient:

$Q=\frac{-\pi r^{4}}{8 \eta} \frac{\Delta P}{\Delta L}$,

where $Q$ is the volume flow/rate of discharge, $r$ is the radius of the tube, $\eta$ is the viscosity of the fluid, and $\Delta P$ is the pressure difference over the flow length $\Delta L$. Darcy's law stated that the rate of discharge is proportional to the viscosity of the fluid and the pressure drop over a given distance, i.e., for a tube with a radius in $r$ :

$Q=\frac{-k \pi r^{2}}{\eta} \frac{\Delta P}{\Delta L}$, 


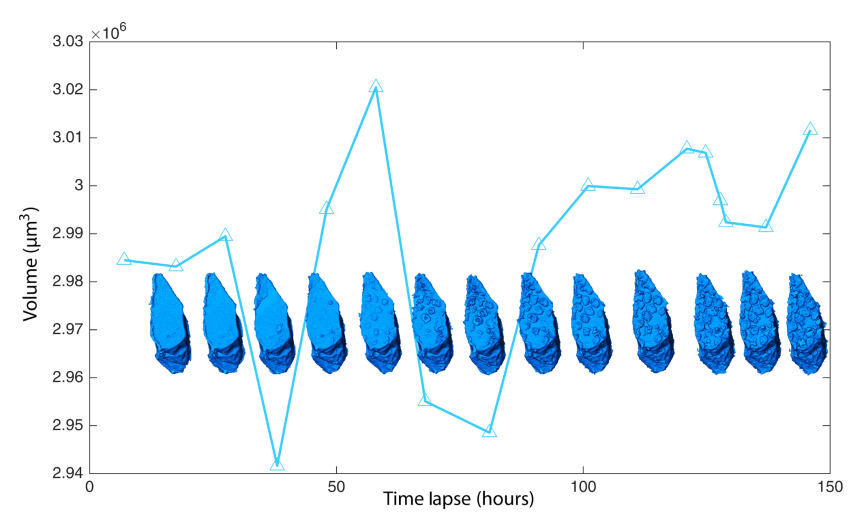

Figure 13. Volume change of an individual olivine grain (total volume of olivine and precipitates) during carbonation reaction in the SGC experiment. The precipitates are idiomorphic and referred to as magnesites (see Zhu et al., 2016). This observed volume change results from a combination of the dissolution of olivine and precipitation of magnesites. Fluctuations of the grain volume manifest the altering dominance of dissolution versus precipitation.

where $k$ is the permeability of the tube. Combining the two equations, $k$ can then be derived as

$k=\frac{r^{2}}{8}$.

In this experiment, $r$ is $\sim 6$ pixels $(360 \mathrm{~nm})$. This yields a permeability of $\sim 1.6 \times 10^{-14} \mathrm{~m}^{2}$, which is high enough to transmit reacting fluids through these channels. Considering the density of wormhole features over the grain, the permeability contributed by the channels could be reduced by 2 orders of magnitude but is still able to transmit fluid.

These intragranular channels contrast the transgranular fractures. But the development of these etch-pitting dissolution channels also provides a fluid path for the reaction and allows a more extensive degree of alteration of the grain. They weaken the grains, make them more susceptible to disintegration and provide nucleation sites of the later fracturing. While sparse in our data, we think that over geological timescales the contribution by dissolution channels to bulk permeability and the advance of the reaction would be significant. However, on the timescale of our experiments, these features alone are insufficient to explain the observed selfsustainability of the reaction considering the scale and density of the dissolution channels, and we argue that the main contribution must come from volume mismatch cracking in our laboratory study.

\subsection{Reaction-induced fracturing}

Olivine carbonation could produce up to a $44 \%$ increase in solid molar volume assuming the reaction can proceed to completion. If such a volume increase takes place, the crystallization pressure generated could be high enough to fracture the host rock (Kelemen et al., 2013; Kelemen and Hirth,
2012). However, experimental studies on olivine carbonation show no evidence of high crystallization forces (van Noort et al., 2017) but rather suggest that precipitation causes the pore space to fill up and halt the reaction before the crystallizationinduced pressure reaches the critical value needed to generate fracture (Hövelmann et al., 2012; van Noort et al., 2017). Our quantitative estimates indicate that in these experiments, the maximum volume expansion is $\sim 5 \%$. This is not enough to break the host rock, as shown in salt crystallization experiments (Scherer, 2004). Indeed, the nanotomography data show only dissolution features such as etch pits and wormholes, with no evidence of cracks in olivine grains surrounded by precipitates (Fig. 11). The lack of evidence for crystallization pressure-induced cracking is consistent with other experimental studies (e.g., Hövelmann et al., 2012).

Based on a microtomography experiment, Zhu et al. (2016) proposed an alternative fracturing mechanism during olivine carbonation where crystallization pressure is not high enough to directly break the host rock. In their experiment, the observed fracture patterns in SGC are analogous to desiccation cracks (e.g., Edelman, 1973; Plummer and Gostin, 1981). In Zhu et al. (2016)'s model, the loose olivine grains inside the cup act as precipitate traps that keep the surface of the cup wall relatively free of precipitation. In the interior of the cup wall though, away from the precipitate traps, the crystallization pressure builds up and causes expansion. While the crystallization pressure is too low to cause shear fracturing of the cup, the expanding cup wall interior stretches the surface of the cup wall and causes it to fail in tension and tear. This is facilitated by the near-constant surface area (which decreases slightly as a result of dissolution). In analogy with desiccation cracks, the resulting fractures form characteristic and systematic polygonal patterns. The first set of fractures intersects at right angles, and all subsequent fractures divide the sample into smaller polygonal domains with increasing intersection angles. Since the fracture pattern develops successively rather than simultaneously, the higher-order fractures form in a different stress geometry and as a result migrate perpendicular to the surfaces generated by the previous fracturing event.

To evaluate the potential of surface stretching as a fracture generating mechanism, we estimated the stress that could be produced by the volume mismatch in the cup wall of SGC. We did so by identifying and tracking grains whose spatial coordinates $(x, y, z)$ changed continually as the sample expanded. Distances between these grains were measured at different times. Our measurements indicate an average expansion of $\sim 9.1 \mu \mathrm{m}$ over a distance of $\sim 260 \mu \mathrm{m}$ from 7 to $125.9 \mathrm{~h}$ after the start of the experiment. The results revealed an axial elongation of $2.78-4.71 \%$ in $\sim 120 \mathrm{~h}$ in the LGC sample. However, little to no expansion was observed at the near-surface area of the sample's cup wall. This would translate into an axial strain of $\sim 0.03$ of the outer layer in order to compensate the volume mismatch. The elastic moduli 


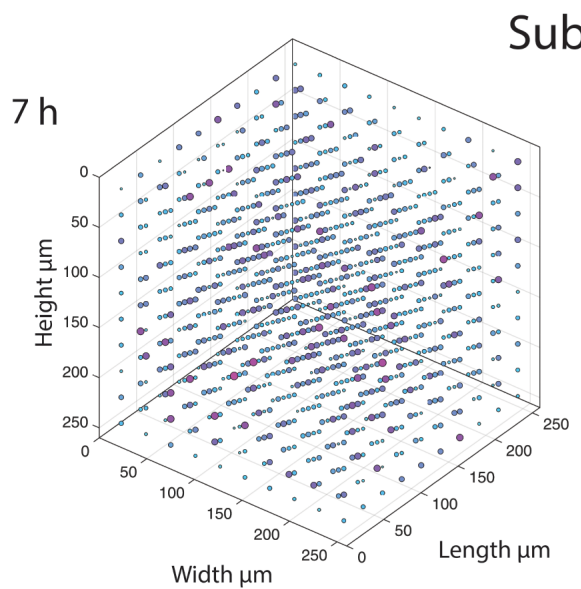

Subvolume 1

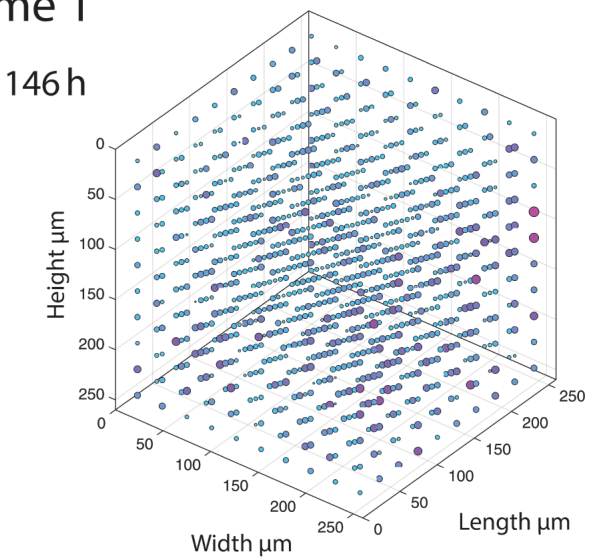

\section{Subvolume 2}
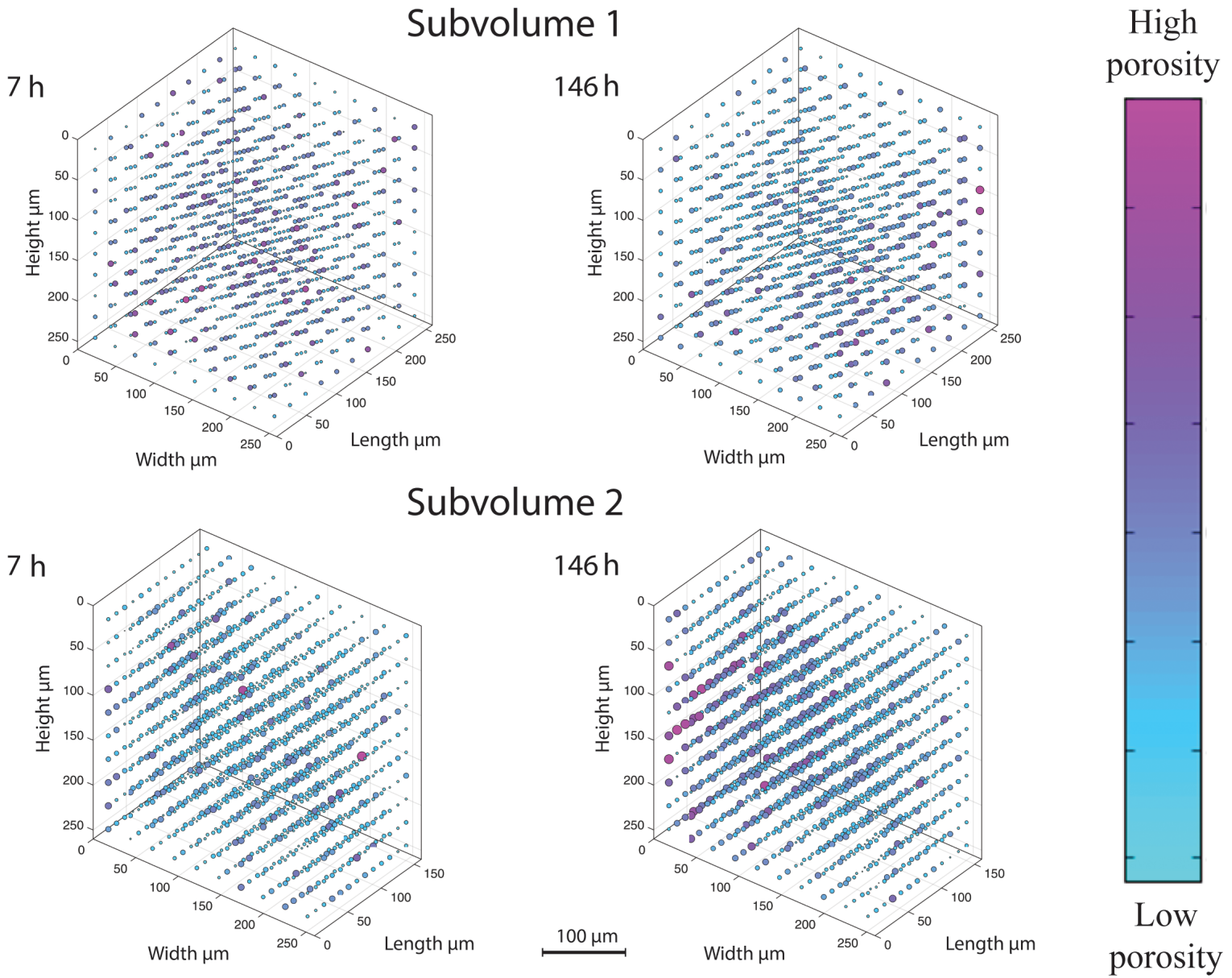

Figure 14. Pore distribution within the subvolumes from SGC sample. For subvolume 1, which contains a more inner part of the sample, porosity is relatively homogenous among the volume. For subvolume 2, as it contains a more outer part of the sample, a concentration of high porosity can be found in the outer edge compared to the inner edge of the subvolume. This contrast in porosity also reflects a non-uniform precipitation which generates stress that fractures the rock.

and strengths of the synthesized porous olivine aggregates are similar to weak sandstones. Using Young's modulus of $\sim 10 \mathrm{GPa}$ yields extensional stresses generated due to the expansion of $\sim 300 \mathrm{MPa}$, easily exceeding the tensile strength of the sample $(\sim 10 \mathrm{MPa})$. Interestingly, our estimate of extensional stress generated by the volume mismatch is of the same magnitude to the stress from crystallization pressurization (e.g., Kelemen et al., 2013). For natural peridotite, Young's moduli range from 108 to $194 \mathrm{GPa}$ (Christensen, 1966), tensile strength is 50 to $290 \mathrm{MPa}$, and spall strength is $\sim 58 \mathrm{MPa}$ (He et al., 1996). An equivalent volume expansion of $\sim 10 \%$ in nature could lead to a stress of $3.24 \mathrm{GPa}$. In both cases, the stress is more than sufficient to fracture the material. However, these are simple estimations of stress and strain made with basic assumptions and local conditions. Considering the extent of the local carbonation reaction and how the expansion in the center is affecting straining of the outer layers, the estimated stress can be considerably lower but should still be in a range that is sufficient to break the material.

To generate the expansion cracks via surface stretching, the volume mismatch must be substantial, which requires keeping the near-surface region free of precipitates. Zhu et al. (2016) suggested that the loose olivine grains inside the sample cup worked as precipitate traps/attractors in this experiment. Because the rate of crystal growth decreases drastically as the curvature of the substrate increases (García et al., 2013; Ziese et al., 2013), large grains in general are preferred sites for precipitation of new crystals. With a size contrast of $\sim 2$ orders of magnitude, the loose olivine grains (100$500 \mu \mathrm{m})$ in the immediate vicinity of the inner cup surface fulfilled the function of precipitate traps and thereby kept precipitation level at the surface of the olivine cup wall low.

We tested the idea of volume mismatch cracking by conducting the LGC experiment. Now, the size contrast between the grains forming the aggregate in the cup wall and the 


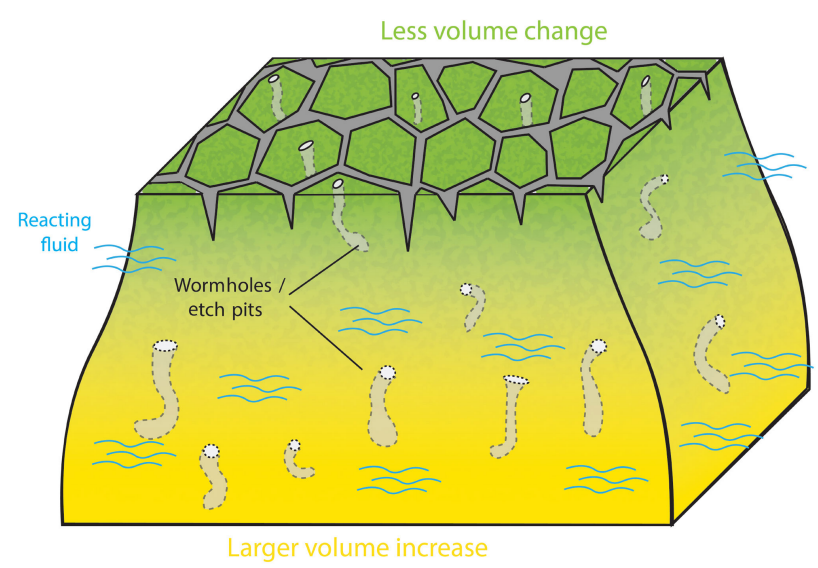

Figure 15. Illustration of porosity generation mechanisms during the olivine carbonation reactions. A combined mechanism of surface cracking and the dissolution channelization plays an important role in the porosity generation. Heterogeneity in the microstructure of the material would cause non-uniform distribution of precipitation. This would lead to the generation of surface cracking via volume mismatch and generate secondary porosity. Dissolution also produces pore spaces and fluid pathways through etch-pitting channelization which makes the grains susceptible to the cracking on a longer timescale.

loose grains inside the cup was significantly reduced, and we expected less efficient precipitate trapping and consequently little to no reaction-induced cracks. The experimental results support this idea. The only planar features observed in the new microtomography experiment are planardissolution-assisted cracking (Figs. 6 and 10a).

A detailed examination of the dissolution channel shown in Fig. 6 revealed no evidence of precipitates there. This places doubt on the crystallization pressure being responsible for fracturing during olivine carbonation. If not, what could be an alternative explanation for the observed fracturing? To further address this question, we examined the porosity evolution and distribution in the 3-D tomographic datasets.

Despite the histogram analysis revealing a bulk increase in the porosity of the cup wall during the experiment, the distribution of these newly generated pores was inhomogeneous in the sample (Figs. 9 and 14). This perturbed the initially homogeneous porosity distribution. This effect became particularly apparent in subvolume 2, which started to exhibit higher porosity where it was closest to the outer surface of the sample after $68 \mathrm{~h}$ (see Videos S2, S3 and S4 for details). The difference in porosity distribution within the sample became more pronounced as the reaction proceeded, with porosity in the outer surface of the cup wall increasing while the porosity inside the cup decreased. In our interpretation, this change in the pore volume reflects a contrast in the precipitation rate where precipitation proceeded more slowly in the outer part compared to the inner part of the sample wall, leading to different rates of expansion and the generation of tensile stresses.

The "expansion cracks via stretching" mechanism can explain the observed microstructure evolution in two subvolumes of SGC (Fig. 4). Since subvolume 2 is located at the periphery of the cup, it would be fractured before subvolume 1 , which is located in the center of the cup wall. This prediction from the expansion cracks via stretching mechanism is consistent with the observed distribution of pore space that most porous area is located close to the periphery. This mechanism also explains why the fractures tend to develop perpendicular to the reaction surfaces. Similar models relating the reactiongenerated stress and fractures have also been used to explain other exfoliation cracks (e.g., Blackwelder, 1925).

In summary, two fundamental observations from our experiments are inconsistent with the "crystallization pressureinduced fracturing" model and form strong arguments against high crystallization forces (i.e., sufficient to break the surrounding rock) (Figs. 11, 14). Firstly, if the cracks were generated directly by crystallization pressure, we should expect them to initiate in a region with intense precipitation and porosity reduction. However, in the outer layer of our sample where the fractures are observed, no precipitates formed prior to the fracturing. Secondly, on the nanoscale, the channels formed by dissolution show hollow and smooth inner surfaces and no precipitation of magnesite (or any other minerals) which shows evidence of low crystallization pressure.

Our detailed analyses provide quantitative support to the "surface cracking via volume mismatch" model first proposed by Zhu et al. (2016). Previous experimental studies on olivine carbonation show that the crystallization force is low (van Noort et al., 2017), suggesting that breaking host rocks by crystallization pressure as in salt crystallization is unlikely, which is in contrast to fracture networks that are commonly observed in naturally occurred serpentinized and carbonated peridotites (Iyer et al., 2008; Macdonald and Fyfe, 1985). We present a resolution to this conundrum by documenting a process that allows fracturing without a high crystallization force.

\subsection{Coupled mechanisms of dissolution and precipitation-driven fracturing}

The findings of this study can be summarized in a mechanism that couples dissolution and precipitation during olivine carbonation. If dissolution and precipitation are heterogeneously distributed in a rock, non-uniform volume expansion can cause breaking of the host rock via surface stretching. In nature, heterogeneity in the porosity and permeability of a rock formation is common, which may cause nonuniform concentration of reaction and distribution of precipitation (Wells et al., 2017). As shown in our study, the resulting volume mismatch could lead to expansion fractures. The fractures provide new fluid pathways and expose fresh reactive surfaces to sustain the carbonation. In the long term, fluid 
pathways may be provided by wormhole etch pitting. Dissolution channels could deteriorate rock strength over longer timescales (Fig. 15).

In a field study on serpentinization of peridotites at ocean ridges, Rouméjon and Cannat (2014) show that the reactioninduced fracturing occurs in the early stages of serpentinization (probably before $20 \%$ of serpentinization) while the rest of the volume increase is accommodated by the serpentine itself and dissolution processes dominate until completion of the reaction. Clearly, natural processes are more complex. Laboratory studies are not capable of simulating nature settings due to the vastly different length and timescale. Instead, we focus on understanding the underlying mechanism of porosity generation during olivine carbonation reaction. Using the coupled dissolution and fracturing model described above, we postulate that at the beginning of a carbonation reaction, dissolution plays an important role in maintaining porosity. As reaction progresses, non-uniform expansion of the rock due to precipitation could lead to fractures. Once the host rock is fractured, accelerated reaction takes place to achieve $100 \%$ carbonation.

In general, several different mechanisms seem to facilitate olivine carbonation and contribute to sustaining it. On relatively short timescales, rapid reaction-induced tensile fracturing could be the dominating mechanism that maintains the reaction, whereas on a longer timescale, dissolution and the formation of channel-like structures may dominate.

\section{Conclusions}

Using synchrotron-based micro- and nanotomography, we documented and quantified the reaction progress during olivine-fluid interaction on the micron scale. This allowed us to identify mechanisms that sustain the reaction despite its large positive volume change.

In summary, our experiment results suggest the following:

- The reaction-induced fracturing observed in our experiments results from non-uniform volume expansion. Tensile stresses arise from heterogeneous precipitation and the resulting contrast in the expansion between a faster-expanding interior and a slower expansion near the surface.

- Even though the dissolution cannot be used alone to explain the sustainability of the experimental timescale olivine carbonation, it provides evidence that dissolution etch pits can provide fluid path and fresh reaction surface for the reaction to proceed. This helps in explaining the naturally occurring complete alteration of peridotite, as the timescale for natural carbonation ranges from thousands to millions of years. Even if the dissolution channelizing would only allow slow fluid flow, it could still induce significant alteration given time.
- The coupled mechanism of dissolution and reactioninduced fracturing accounts for maintaining the reaction processes during olivine carbonation. It explains on different time and space scales the formation of observed natural outcrops of completely carbonated peridotite.

- The results from our experimental study also provide new insights into the application of $\mathrm{CO}_{2}$ mineral sequestration.

Data availability. Upon request, the underlying data will be made available for scientific research purposes, wherever it is legal and ethical.

\section{The Supplement related to this article is available online at https://doi.org/10.5194/se-9-879-2018-supplement.}

Author contributions. WZ obtained the funding and conceived the experiment; TX, WZ, FF and HL performed the experiments; TX analyzed the data; TX and all co-authors wrote the paper.

Competing interests. The authors declare that they have no conflict of interest.

Acknowledgements. This work is supported by the Department of Energy, Office of Science, the Office of Basic Energy Sciences, Chemical Sciences, Geosciences, \& Biosciences Division under award no. DE-FG-0207ER15916, and by the National Science Foundation under grant no. EAR-1551300. We would like to thank the three anonymous referees for their suggestions and comments. We would also like to thank the editor Michael Heap for his assistance and handling of the manuscript.

Edited by: Michael Heap

Reviewed by: three anonymous referees

\section{References}

Andreani, M., Luquot, L., Gouze, P., Godard, M., Hoise, E., and Gibert, B.: Experimental Study of Carbon Sequestration Reactions Controlled by the Percolation of CO-Rich Brine through Peridotites, Environ. Sci. Technol., 43, 1226-1231, https://doi.org/10.1021/es8018429, 2009.

Bedford, J., Fusseis, F., Leclère, H., Wheeler, J., and Faulkner, D.: A 4D view on the evolution of metamorphic dehydration reactions, Sci. Rep., 7, 6881, https://doi.org/10.1038/s41598-017-07160-5, 2017.

Beinlich, A. and Austrheim, H.: In situ sequestration of atmospheric $\mathrm{CO}_{2}$ at low temperature and surface cracking of serpentinized peridotite in mine shafts, Chem. Geol., 332-333, 32-44, https://doi.org/10.1016/j.chemgeo.2012.09.015, 2012 
Beinlich, A., Plümper, O., Hövelmann, J., Austrheim, H., and Jamtveit, B.: Massive serpentinite carbonation at Linnajavri, N-Norway, Terra Nova, 24, 446-455, https://doi.org/10.1111/j.1365-3121.2012.01083.x, 2012.

Blackwelder, E.: Exfoliation as a Phase of Rock Weathering, J. Geol., 33, 793-806, 1925.

Christensen, N. I.: Elasticity of Ultrabasic Rocks, J. Geophys. Res., 71, 5921-5931, https://doi.org/10.1029/JZ071i024p05921, 1966.

Cloetens, P., Barrett, R., Baruchel, J., Guigay, J. P., and Schlenker, M.: Phase objects in synchrotron radiation hard x-ray imaging, J. Phys. D. Appl. Phys., 29, 133-146, https://doi.org/10.1088/00223727/29/1/023, 1996.

Darcy, H.: Les fontaines publiques de la ville de Dijon, Recherche, 647, available at: http://scholar.google.com/scholar?hl= en\&btnG=Search\&q=intitle:Les+fontaines+publiques+de+ la+ville+de+dijon\#0 (last access: 5 July 2018), 1856.

Deschamps, F., Godard, M., Guillot, S., and Hattori, K.: Geochemistry of subduction zone serpentinites: A review, Lithos, 178, 96127, https://doi.org/10.1016/j.lithos.2013.05.019, 2013.

Eberhardt, E., Stimpson, B., and Stead, D.: Effects of Grain Size on the Initiation and Propagation Thresholds of Stressinduced Brittle Fractures, Rock Mech. Rock Eng., 32, 81-99, https://doi.org/10.1007/s006030050026, 1999.

Edelman, N.: Tension cracks parallel with the axial plane, B. Geol. Soc. Finland, 45, 61-65, 1973.

Emmanuel, S. and Berkowitz, B.: Suppression and stimulation of seafloor hydrothermal convection by exothermic mineral hydration, Earth Planet. Sc. Lett., 243, 657-668, https://doi.org/10.1016/j.epsl.2006.01.028, 2006.

Escartín, J., Hirth, G., and Evans, B.: Effects of serpentinization on the lithospheric strength and the style of normal faulting at slow-spreading ridges, Earth Planet. Sc. Lett., 151, 181-189, https://doi.org/10.1016/S0012-821X(97)81847-X, 1997.

Evans, B. W.: Metamorphism of alpine peridotite and serpentinite, Annu. Rev. Earth Pl. Sc., 5, 397-447, https://doi.org/10.1146/annurev.ea.05.050177.002145, 1977.

Falk, E. S. and Kelemen, P. B.: Geochemistry and petrology of listvenite in the Samail ophiolite, Sultanate of Oman: Complete carbonation of peridotite during ophiolite emplacement, Geochim. Cosmochim. Ac., 160, 70-90, https://doi.org/10.1016/j.gca.2015.03.014, 2015.

Fryer, P., Mottl, M., Johnson, L., Haggerty, J., Phipps, S., and Maekawa, H.: Serpentine bodies in the forearcs of western pacific convergent margins: Origin and associated fluids, Geoph. Monog. Series, 88, 259-279, 1995.

Fusseis, F., Schrank, C., Liu, J., Karrech, A., Llana-Fúnez, S., Xiao, X., and Regenauer-Lieb, K.: Pore formation during dehydration of a polycrystalline gypsum sample observed and quantified in a time-series synchrotron X-ray micro-tomography experiment, Solid Earth, 3, 71-86, https://doi.org/10.5194/se-3-712012, 2012.

Fusseis, F., Xiao, X., Schrank, C., and De Carlo, F.: A brief guide to synchrotron radiation-based microtomography in (structural) geology and rock mechanics, J. Struct. Geol., 65, 1-16, https://doi.org/10.1016/j.jsg.2014.02.005, 2014a.

Fusseis, F., Steeb, H., Xiao, X., Zhu, W. L., Butler, I. B., Elphick, S., and Mäder, U.: A low-cost X-ray-transparent experimental cell for synchrotron-based X-ray microtomography studies under geological reservoir conditions, J. Synchrotron Radiat., 21, 251253, https://doi.org/10.1107/S1600577513026969, 2014b.

García, N. A., Register, R. A., Vega, D. A., and Gómez, L. R.: Crystallization dynamics on curved surfaces, Phys. Rev. E-Stat. Nonlinear, Soft Matter Phys., 88, 012306, https://doi.org/10.1103/PhysRevE.88.012306, 2013.

Gislason, S. R., Wolff-Boenisch, D., Stefansson, A., Oelkers, E. H., Gunnlaugsson, E., Sigurdardottir, H., Sigfusson, B., Broecker, W. S., Matter, J. M., and Stute, M.: Mineral sequestration of carbon dioxide in basalt: A pre-injection overview of the CarbFix project, Int. J. Greenh. Gas Con., 4, 537-545, https://doi.org/10.1016/j.ijggc.2009.11.013, 2010.

Goff, F. and Lackner, K. S.: Carbon dioxide sequestering using ultramafic rocks, Environ. Geosci., 5, 89-101, 1998.

Grandstaff, D. E.: Changes in surface area and morphology and the mechanism of forsterite dissolution, Geochim. Cosmochim. Ac., 42, 1899-1901, https://doi.org/10.1016/0016-7037(78)90245-4, 1978.

Gürsoy, D., De Carlo, F., Xiao, X., and Jacobsen, C.: TomoPy: A framework for the analysis of synchrotron tomographic data, J. Synchrotron. Radiat., 21, 1188-1193, https://doi.org/10.1107/S1600577514013939, 2014.

Hansen, L. D., Dipple, G. M., Gordon, T. M., and Kellett, D. A.: Carbonated serpentinite (listwanite) at Atlin, British Columbia: A geological analogue to carbon dioxide sequestration, Can. Mineral., 43, 225-239, https://doi.org/10.2113/gscanmin.43.1.225, 2005.

He, H., Jin, X., Jing, F., and Ahrens, T. J.: Characteristic of dynamic tensile fracture in augite-peridotite, in: AIP Conference Proceedings, AIP, vol. 370, 593-596, 1996.

Heilbronner, R. and Barrett, S.: Image Analysis in Earth Sciences, Springer, Berlin, Heidelberg, 2014.

Hövelmann, J., Austrheim, H., and Jamtveit, B.: Microstructure and porosity evolution during experimental carbonation of a natural peridotite, Chem. Geol., 334, 254-265, https://doi.org/10.1016/j.chemgeo.2012.10.025, 2012.

Iyer, K., Jamtveit, B., Mathiesen, J., Malthe-Sørenssen, A., and Feder, J.: Reaction-assisted hierarchical fracturing during serpentinization, Earth Planet. Sc. Lett., 267, 503-516, https://doi.org/10.1016/j.epsl.2007.11.060, 2008.

Jamtveit, B., Putnis, C. V., and Malthe-Sørenssen, A.: Reaction induced fracturing during replacement processes, Contrib. Mineral. Petr., 157, 127-133, https://doi.org/10.1007/s00410-008-0324-y, 2009.

Jamtveit, B., Kobchenko, M., Austrheim, H., Malthe-Sørenssen, A., Røyne, A., and Svensen, H.: Porosity evolution and crystallization-driven fragmentation during weathering of andesite, J. Geophys. Res.-Sol. Ea., 116, 1-12, https://doi.org/10.1029/2011JB008649, 2011.

Johannes, W.: An experimental investigation of the system $\mathrm{MgO}-\mathrm{SiO}_{2}-\mathrm{H}_{2} \mathrm{O}-\mathrm{CO}_{2}$, Am. J. Sci., 267, 1083-1104, https://doi.org/10.2475/ajs.267.9.1083, 1969.

Kaestner, A., Lehmann, E., and Stampanoni, M.: Imaging and image processing in porous media research, Adv. Water Resour., 31, 1174-1187, https://doi.org/10.1016/j.advwatres.2008.01.022, 2008.

Kelemen, P. B. and Matter, J. M.: In situ carbonation of peridotite for $\mathrm{CO}_{2}$ storage, P. Natl. Acad. Sci. USA, 105, 17295-17300, https://doi.org/10.1073/pnas.0805794105, 2008. 
Kelemen, P. B. and Hirth, G.: Reaction-driven cracking during retrograde metamorphism: Olivine hydration and carbonation, Earth Planet. Sc. Lett., 345-348, 81-89, https://doi.org/10.1016/j.epsl.2012.06.018, 2012.

Kelemen, P. B., Matter, J., Streit, E. E., Rudge, J. F., Curry, W. B., and Blusztajn, J.: Rates and Mechanisms of Mineral Carbonation in Peridotite: Natural Processes and Recipes for Enhanced, in situ $\mathrm{CO}_{2}$ Capture and Storage, Annu. Rev. Earth Planet. Sc., 39, 545-576, https://doi.org/10.1146/annurev-earth092010-152509, 2011.

Kelemen, P. B., Savage, H., and Hirth, G.: Reaction-Driven Cracking During Mineral Hydration, Carbonation and Oxidation, edited by: Poromechanics, V., vol. c, American Society of Civil Engineers, Reston, VA, 823-826, https://doi.org/10.1061/9780784412992.099, 2013.

King, H. E., Plümper, O., and Putnis, A.: Effect of Secondary Phase Formation on the Carbonation of Olivine, Environ. Sci. Technol., 44, 6503-6509, https://doi.org/10.1021/es9038193, 2010.

Lisabeth, H., Zhu, W., Xing, T., and De Andrade, V.: Dissolution-Assisted Pattern Formation During Olivine Carbonation, Geophys. Res. Lett., 44, 9622-9631, https://doi.org/10.1002/2017GL074393, 2017a.

Lisabeth, H. P., Zhu, W., Kelemen, P. B., and Ilgen, A.: Experimental evidence for chemo-mechanical coupling during carbon mineralization in ultramafic rocks, Earth Planet. Sc. Lett., 474, 355-367, https://doi.org/10.1016/j.epsl.2017.06.045, 2017b.

Macdonald, A. H. and Fyfe, W. S.: Rate of serpentinization in seafloor environments, Tectonophysics, 116, 123-135, https://doi.org/10.1016/0040-1951(85)90225-2, 1985.

Mani, D., Nirmal Charan, S., and Kumar, B.: Assessment of carbon dioxide sequestration potential of ultramafic rocks in the greenstone belts of southern India, Curr. Sci., 94, 53-60, 2008.

Moore, D. E., Lockner, D. A., Summers, R., Ma, S., and Byerlee, J. D.: Strength of crisolite-serpentinite gouge under hydrothermal conditions: Can it explain a weak San Andreas fault?, Geology, 24, 1041-1044, https://doi.org/10.1130/00917613(1996)024<1041:SOCSGU>2.3.CO;2, 1996.

Nasir, S., Al Sayigh, A. R., Al Harthy, A., Al-Khirbash, S., AlJaaidi, O., Musllam, A., Al-Mishwat, A., and Al-Bu'saidi, S.: Mineralogical and geochemical characterization of listwaenite from the Semail Ophiolite, Oman, Chem. Erde-Geochem., 67, 213-228, https://doi.org/10.1016/j.chemer.2005.01.003, 2007.

Peuble, S., Andreani, M., Gouze, P., Pollet-Villard, M., Reynard, B., and Van de Moortele, B.: Multi-scale characterization of the incipient carbonation of peridotite, Chem. Geol., 476, 150-160, https://doi.org/10.1016/j.chemgeo.2017.11.013, 2018.

Plummer, P. S. and Gostin, V. A.: Shrinkage cracks: desiccation or synaeresis?, J. Sediment. Petrol., 51, 11471156 https://doi.org/10.1306/212F7E4B-2B24-11D78648000102C1865D, 1981.

Poiseuille, J. L. M.: Recherches experimentales sur le mouvement des liquides dans les tubes de tres petits diametres, Imprimerie Royale, available at: https://www.irphe.fr/ clanet/otherpaperfile/ articles/Poiseuille/poiseuille1840a.pdf (last access: 5 July 2018), 1844.

Power, I. M., Harrison, A. L., Dipple, G. M., Wilson, S. A., Kelemen, P. B., Hitch, M., and Southam, G.: Carbon Mineralization: From Natural Analogues to Engineered Systems, Rev. Mineral.
Geochem., 77, 305-360, https://doi.org/10.2138/rmg.2013.77.9, 2013.

Rouméjon, S. and Cannat, M.: Serpentinization of mantle-derived peridotites at mid-ocean ridges: Mesh texture development in the context of tectonic exhumation, Geochem. Geophy. Geosy., 15, 2354-2379, https://doi.org/10.1002/2013GC005148, 2014.

Røyne, A. and Jamtveit, B.: Pore-Scale Controls on ReactionDriven Fracturing, Rev. Mineral. Geochem., 80, 25-44, https://doi.org/10.2138/rmg.2015.80.02, 2015.

Rudge, J. F., Kelemen, P. B., and Spiegelman, M.: A simple model of reaction-induced cracking applied to serpentinization and carbonation of peridotite, Earth Planet. Sc. Lett., 291, 215-227, https://doi.org/10.1016/j.epsl.2010.01.016, 2010.

Saldi, G. D., Jordan, G., Schott, J., and Oelkers, E. H.: Magnesite growth rates as a function of temperature and saturation state, Geochim. Cosmochim. Ac., 73, 5646-5657, https://doi.org/10.1016/j.gca.2009.06.035, 2009.

Scherer, G. W.: Stress from crystallization of salt, Cem. Concr. Res., 34, 1613-1624, https://doi.org/10.1016/j.cemconres.2003.12.034, 2004.

Singh, S. K.: Relationship among fatigue strength, mean grain size and compressive strength of a rock, Rock Mech. Rock Eng., 21, 271-276, https://doi.org/10.1007/BF01020280, 1988.

Ulven, O. I., Storheim, H., Austrheim, H., and Malthe-Sørenssen, A.: Fracture initiation during volume increasing reactions in rocks and applications for $\mathrm{CO}_{2}$ sequestration, Earth Planet. Sc. Lett., 389, 132-142, https://doi.org/10.1016/j.eps1.2013.12.039, 2014.

van Noort, R., Wolterbeek, T., Drury, M., Kandianis, M., and Spiers, C.: The Force of Crystallization and Fracture Propagation during In-Situ Carbonation of Peridotite, Minerals, 7, 190, https://doi.org/10.3390/min7100190, 2017.

Velbel, M. A.: Dissolution of olivine during natural weathering, Geochim. Cosmochim. Ac., 73, 6098-6113, https://doi.org/10.1016/j.gca.2009.07.024, 2009.

Velbel, M. A. and Ranck, J. M.: Etch pits on naturally altered olivine from dunites of the Appalachian Blue Ridge Mountains, North Carolina, USA, Mineral. Mag., 72, 145-148, https://doi.org/10.1180/minmag.2008.072.1.145, 2008.

Wells, R. K., Xiong, W., Sesti, E., Cui, J., Giammar, D., Skemer, P., Hayes, S. E., and Conradi, M. S.: Spatially-variable carbonation reactions in polycrystalline olivine, Geochim. Cosmochim. Ac., 204, 252-266, https://doi.org/10.1016/j.gca.2017.02.003, 2017.

Weyl, P. K.: Pressure solution and the force of crystallization: a phenomenological theory, J. Geophys. Res., 64, 2001-2025, https://doi.org/10.1029/JZ064i011p02001, 1959.

Wilson, M. J.: Weathering of the primary rock-forming minerals: processes, products and rates, Clay Miner., 39, 233-266, https://doi.org/10.1180/0009855043930133, 2004.

Wilson, M. J. and Jones, D.: Lichen weathering of minerals: implications for pedogenesis, Geol. Soc. London, Spec. Publ., 11, 5-12, https://doi.org/10.1144/GSL.SP.1983.011.01.01, 1983.

Winkler, E. M. and Singer, P. C.: Crystallization pressure of salts in stone and concrete, Bull. Geol. Soc. Am., 83, 3509-3514, https://doi.org/10.1130/00167606(1972)83[3509:CPOSIS]2.0.CO;2, 1972.

Zhu, W., Montesi, L. G. J., and Wong, T. F.: Shear-enhanced compaction and permeability reduction: Triaxial extension 
tests on porous sandstone, Mech. Mater., 25, 199-214, https://doi.org/10.1016/S0167-6636(97)00011-2, 1997.

Zhu, W., Fusseis, F., Lisabeth, H. P., Xing, T., Xiao, X., De Andrade, V., and Karato, S. I.: Experimental evidence of reaction-induced fracturing during olivine carbonation, Geophys. Res. Lett., 43, 9535-9543, https://doi.org/10.1002/2016GL070834, 2016.
Ziese, F., Maret, G., and Gasser, U.: Heterogeneous nucleation and crystal growth on curved surfaces observed by real-space imaging, J. Phys. Condens. Matter, 25, 375105, https://doi.org/10.1088/0953-8984/25/37/375105, 2013. 